\title{
Commenting on the Umbrella Movement: A Framing Analysis of Online News and Audience Discourse
}

\author{
by \\ Yanchao An
}

A thesis submitted to the Faculty of Graduate and Postdoctoral Affairs in partial fulfillment of the requirements for the degree of

Master of Arts

in

Communication Studies

Carleton University

Ottawa, Ontario

C 2016, Yanchao An 


\begin{abstract}
This thesis examines the relationship between news frames and audience comments surrounding Hong Kong's 2014 Umbrella Movement. Motivated by inconsistent reports on the "pro-democracy" movement, this study questions: How was the Umbrella Movement framed across mainstream news outlets, and what are audiences saying? Employing a dual framing and discourse analysis, this study examined news coverage on the Umbrella Movement and the discussions generated by commenters across the online editions of three national newspapers: South China Morning Post, the Washington Post, and Global Times. The findings revealed that news frames were connected to a nation's history and enduring societal values. While news outlets had defined positions towards the movement, the key findings revealed that comments were predominantly generated by critical audiences who challenged dominant news narratives. In doing so, they generate interactive communicative spaces that enable alternative perspectives to emerge, rendering comment sections as valuable resources when studying news frames online.
\end{abstract}




\section{Acknowledgements}

I was once told that writing a thesis is like driving at night with the headlights on. You may not be able to see the final destination, but you will eventually get there. Throughout this project, I had many shining headlights and helpful road signs that directed me to the end.

I would like to extend my gratitude to my supervisor, Merlyna Lim. Thank you for not only providing great moral and academic support for this project, but also for sharing your many delightful stories. I am also grateful to have Ben Woo as part of my committee. Thank you, Ben, for your sharp attention to detail and for providing valuable insights to this project. It goes without mention that the entire Communication Studies faculty has been tremendously encouraging throughout this process. A special thanks goes to Coleen for always being so kind and helpful.

Thank you to all my colleagues for making this experience more bright and colourful. I am inspired by your positivity, intelligence, and ability to complete quality work in the office! You will always be my commrads.

Lastly, I would like to say a huge thank you to my close friends and family for all your love and support. To my mom, I strive to be as hard working and motivated as you each day. 


\section{Table of Contents}

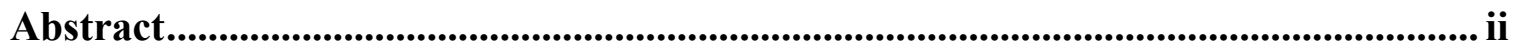

Acknowledgements ............................................................................................................iii

Table of Contents ............................................................................................................... iv

List of Figures.......................................................................................................... vi

List of Acronyms ....................................................................................................................... vii

1 Chapter: The 2014 Umbrella Movement of Hong Kong............................................. 8

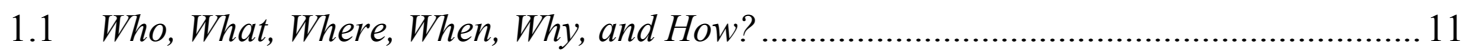

1.2 Emergent Research on the Umbrella Movement ............................................................. 14

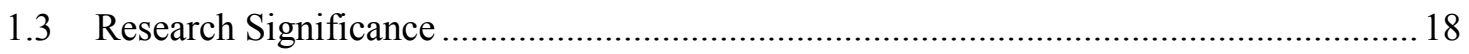

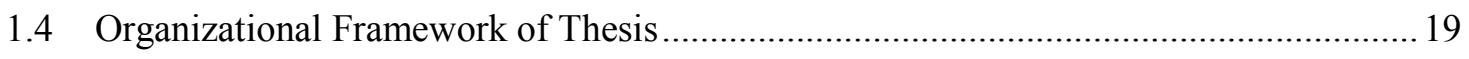

2 Chapter: Legitimizing Social Reality through Framing ........................................... 22

2.1 Framing of Social Movements: Literature Review and Key Concepts ..........................23

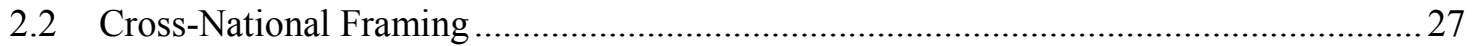

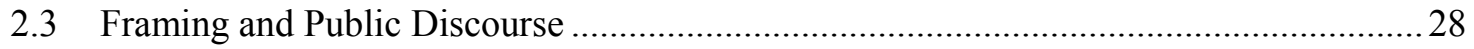

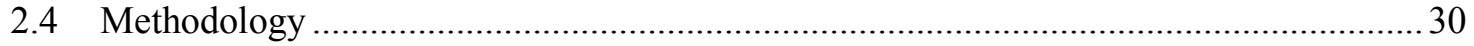

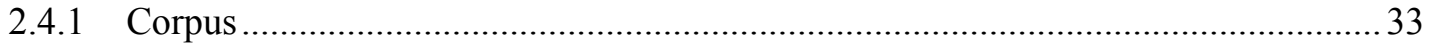

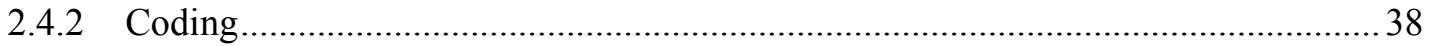

3 Chapter: Contextualizing the Umbrella Movement through History .................. 39

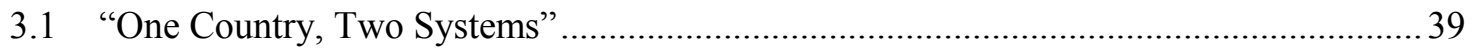

3.2 Brewing Dissatisfaction under Hong Kong's Political Structure................................... 41

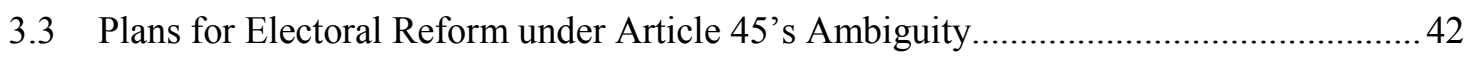

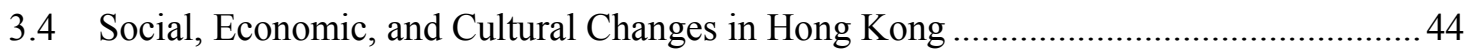

3.5 The Turning Point of Hong Kong's Pro-Democracy Movement ....................................47

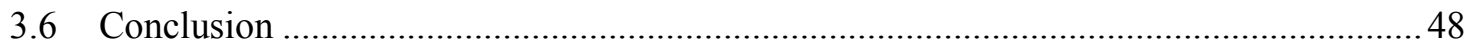

4 Chapter: Finding Key News Frames............................................................................ 50

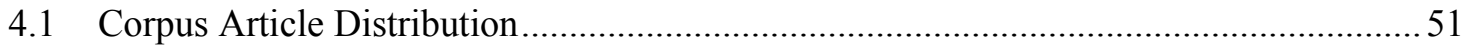

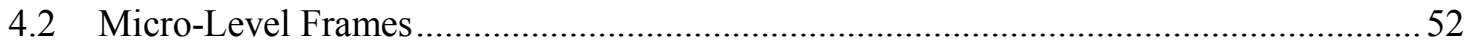

4.2.1 Causal Frames: NPCSC's Decision as the Catalyst of Protest .................................53

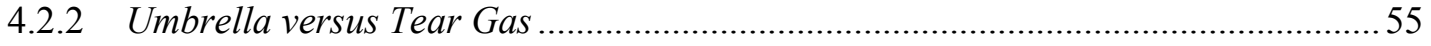




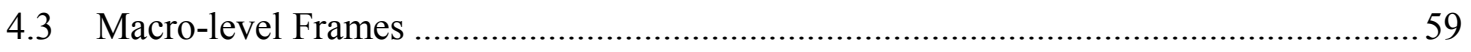

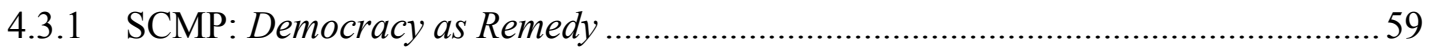

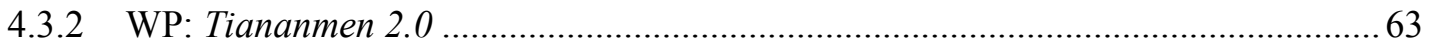

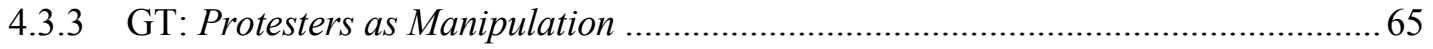

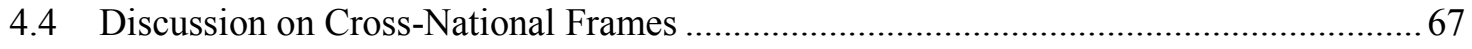

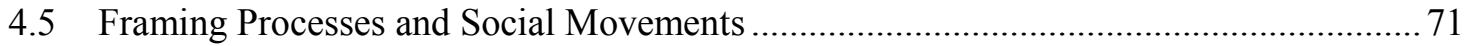

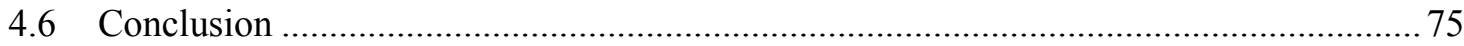

5 Chapter: Commenting on the Umbrella Movement............................................... 77

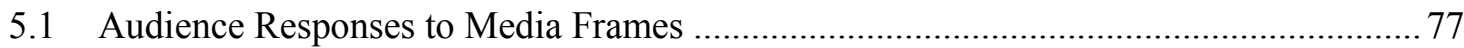

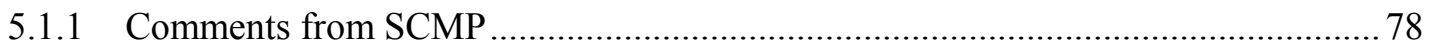

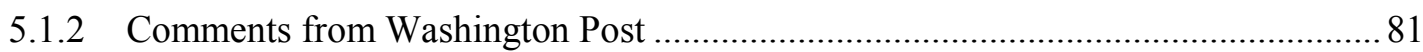

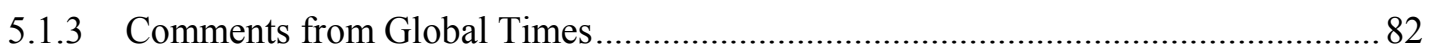

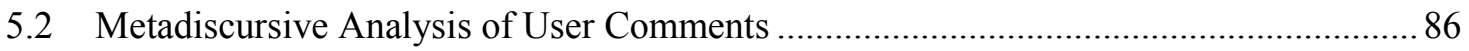

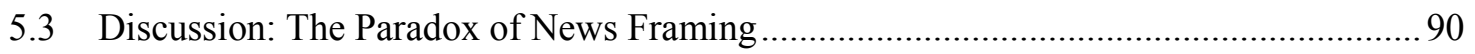

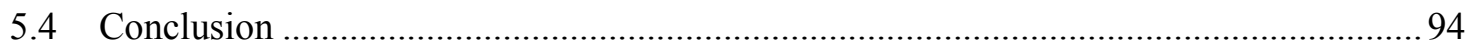

6 Chapter: Conclusion ........................................................................................................ 96

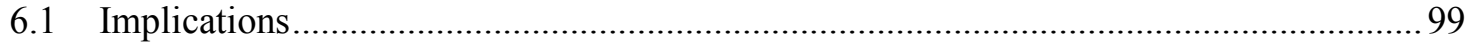

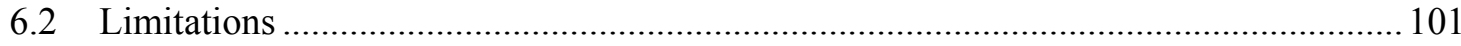

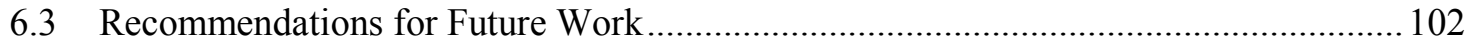

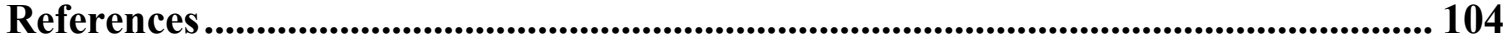

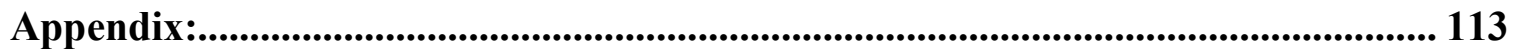




\section{List of Figures}

Figure 1: Exemplifying the Elements in Constructing a Frame Package .......... 34

Figure 2: Distribution of Online News Articles .............................. 49 


\section{List of Acronyms}

CPC: Communist Party of China

GT: Global Times

HKSAR: Hong Kong Special Administrative Region

NPCSC: the Standing Committee of the National's People Congress

OCLP: Occupy Central with Love and Peace

PRC: People's Republic of China

SCMP: South China Morning Post (International)

WP: the Washington Post 


\section{Chapter: The 2014 Umbrella Movement of Hong Kong}

On September 28, 2014, thousands of protesters marched into the Central government district of Hong Kong, demanding the right to elect Hong Kong's 2017 Chief Executive through methods of universal suffrage, commonly defined by one person, one vote. In an attempt to control the crowds practicing methods of civil disobedience, Hong Kong police shot eighty-seven canisters of tear gas and pepper spray onto the peaceful protesters, who primarily consisted of students. As an act of defense, protesters used the closest tools at hand, their umbrellas, to deflect the harmful showers. Swarms of protesters formed a sea of umbrellas, creating a shield against armed police.

I have inadvertently practiced methods of framing through my introduction of the Umbrella Movement. Framing is a natural process in storytelling and a common practice in news reporting. By selectively choosing which words to use, which actors to include, and what information to provide, my description of the Umbrella Movement cannot escape the practice of framing. The way in which I have introduced the Umbrella Movement is not too far detached from mainstream news coverage of the movement. In reality, the Umbrella Movement is a product of historical tensions between the people of Hong Kong and the People's Republic of China (PRC). Some international mainstream news outlets have coined the movement as the Umbrella Revolution and portrayed the movement as a spontaneous outburst of citizen engagement that emerged overnight. However, protesters did not wish to start a revolution or signal the movement as a threat to the Central government, asking everyone to refer to the movement as the Umbrella Movement instead. The key mobilizers of the protests were Hong Kong student groups, 
as well as the activist group, Occupy Central with Love and Peace (OCLP). Ever since January 2013, OCLP has been advocating for genuine universal suffrage in Hong Kong. However, the push for equal representation in direct elections has been a concern in Hong Kong for decades, even prior to the Handover in 1997, when Britain returned Hong Kong back to China. These campaigns were left out of the limelight until September 28, 2014, when news of protests in Hong Kong splashed international headlines the following morning.

This thesis is concerned with professionally produced discourses by mainstream news media as well as more organically generated discourses from corresponding online user comments. Exploring discourses produced by certain audiences can lead to insights that mainstream news media may not have included. Communication and social media scholars have often studied how mainstream media frame social movements, as their stories have a powerful impact on the reception of a movement by audiences, protesters, and members of authorities (Benford and Snow, 2000; Boyle, McLeod and Armstrong, 2012; Gottlieb, 2015; Zald and McCarthy, 1987). However, there is limited research on framing that encompasses both mainstream newspapers and corresponding responses from online audiences. This research aims to fill this gap by studying news discourse from the online editions of three national newspapers: South China Morning Post International Edition (SCMP), the Washington Post (WP), and Global Times (GT). Many online mainstream news outlets offer interactive spaces for discussion, where audiences can add their response to the news content, author's stance, as well as other commenters. As online news readership grows steadily (Newman, Levy, and Nielson, 2015), framing research should acknowledge these rising trends as an opportune method for studying 
observable audience reactions in a digital environment. My research also makes a contribution to the smaller body of cross-national framing studies, as the corpus encompasses three mainstream news outlets from different national regions to compare how news coverage differs. Although readers of online news are not constrained by national boundaries, the content that they read may still hold apparent national ideologies embedded in its news discourse. Thus, my research makes contributions to the role of the framing of social movements in mainstream media and the relationship between online news articles and commenters, while providing a greater understanding of the Umbrella Movement.

While this research aims to achieve a greater understanding of how the movement itself is represented, it also contributes to existing literature on the framing of social movements. The goal of this thesis is to reveal the dominant media frames from professional news discourses as well as audience responses to these frames through online commenters. The findings demonstrate how the role of framing is changing due to audiences commenting on online news articles. Instead of one dominant frame being presented in mainstream news discourses, an abundance of alternative perspectives are revealed in the comments. Commenters who disagree, counter, or reject news frames fuel online discussions as they justify their position with anecdotal evidence and external sources. In the comment section of these articles, news frames are able to create interactive spaces of communication that set the stage for productive discourse. In the case of the Umbrella Movement, audience commenters were able to reinforce and strengthen certain news frames, while contesting others, allowing commenters to contribute their own analyses in making sense of the movement. In turn, these more 
engaged audiences generate a wider representation of the events and issues that shape the Umbrella Movement.

\subsection{Who, What, Where, When, Why, and How?}

Prior to being referred to as the Umbrella Movement, Occupy Central with Love and Peace (OCLP) was the main public activist group that campaigned for Hong Kong to achieve universal suffrage by 2017. OCLP defines themselves as a "nonviolent direct action movement that demands genuine universal suffrage in Hong Kong in compliance with international law" (OCLP, n.d.). What OCLP defines as universal suffrage is the ability to grant every individual in Hong Kong the right to vote for its Chief Executive and the ability to run for office without restrictions (OCLP, n.d.). OCLP was founded by Benny Tai, a law professor at the University of Hong Kong and his two colleagues, Professor Chan Kin-Man and Reverend Chu Yiu-Ming, on January 16, 2013 (OCLP, n.d.). This group was formed after Benny Tai drafted a proposal titled Civil Disobedience's Mass Destruction Weapon. The proposal demanded a civil disobedience campaign of 10,000 participants to occupy the Central government headquarters to pressure the government in Beijing to allow citizens to elect and vote for Hong Kong's Chief Executive in 2017 through methods of universal suffrage. Hence, the movement was known locally as Occupy Central or the Occupy Central Movement.

The government of Hong Kong, also known as the Hong Kong Special Administrative Region (HKSAR), issued a warning against OCLP in the case of 
occupying protests. Chief Executive C.Y. Leung attempted to stifle the movement by threatening the public during its first stages:

Once the occupy action takes place, there will be no possibility of it being lawful or peaceful. The government will not tolerate law-breaking activities. To organize unlawful activities that disrupt the law and order ... leads one to question the motive: is it breaking the law for the sake of it? (Quoted in Lam, 2014, p. 464).

Other members of the Executive Council predicted the movement would be "economic suicide," potentially damaging Hong Kong's reputation as an international financial centre (Lam, 2014, p. 464). Along with members of the HKSAR, public responses from Hongkongers were also divided when it came to supporting OCLP's initiatives. According to a survey by Ming Pao in 2013, 51 percent of respondents opposed OCLP's suggestion to occupy Central to fight for universal suffrage, while 25 percent of respondents supported the movement, and 25 percent were undecided or did not know (Lam, 2014). However, on August 31, 2014, the Central government body in Beijing, the Standing Committee of the National People's Congress (NPCSC), released a statement announcing that candidates for Chief Executive would be chosen by a nomination committee in Beijing that screens candidates before allowing the people of Hong Kong to vote through methods of "universal suffrage". The screening of candidates undermines the impact of direct elections and deprives the people of Hong Kong the fair choice of whom they wish to elect on their own. This statement generated more pressure for members of OCLP to organize and take action sooner. OCLP originally planned to occupy Central on October 1,2014 , the $65^{\text {th }}$ anniversary of the PRC. However, after the NPCSC's decision was released at the end of August, student boycotts were unexpectedly the first to publicly demonstrate their discontent. International news reports highlighted 
the leader of the movement as Joshua Wong, a seventeen-year-old student who created Scholarism (Sagan, 2014). Scholarism is a student organization that originated in 2011 and led multiple movements that aimed to stifle the influence of mainland policies, such as the national education plan that was perceived to be "brainwashing" students with proBeijing ideologies (Scholarism, n.d.). Another student group involved was the Hong Kong Federation of Students (HKFS), which consists of several university union groups. These two student groups demanded for the withdrawal of the NPCSC's decision in August 2014, but the Central government did not budge.

On September 27, 2014, students began to demonstrate outside the Central government offices and reached out for support from members of OCLP. With the students' momentum, Benny Tai led his group into the heart of the city's district on September 28. The mass demonstrations alarmed the authorities that, in response, released 87 rounds of tear gas among occupying protesters. Protesters holding umbrellas in front of the police blockade acted as the first line of defense. Other protesters used saran wrap and goggles to protect themselves from tear gas and pepper spray. Images of conflict between authorities and protesters spread quickly among mainstream media and social media, sprouting intense responses that generated more protesters and supporters for the movement. Over the course of one week, the movement expanded outside the Central district of Hong Kong into Mongkok, Kowloon, and Causeway Bay.

After seventy-nine days of persistent protesters camping and demonstrating on the streets, the movement resulted in a stalemate. The government would not budge on their terms, and the protesters were becoming more unpopular due to the inconveniences they were creating on the city's streets. Allowing the protests to persist over the following 
weeks without the use of force was a strategic decision by the government that allowed the public to become naturally more dissatisfied with the movement. Parents wanted their children to go back to school, and local shop owners were eager to resume business. The protesters slowly dissipated over the following weeks. On December 3, 2014, Professor Chan Kin-Man and Reverend Chu Yiu-Ming turned themselves into the police as a symbolic way to end the protests, while also reminding citizens of their continuous fight for democracy in Hong Kong.

\subsection{Emergent Research on the Umbrella Movement}

Despite the Umbrella Movement being a fairly recent and ongoing movement, research on this topic has developed among scholars. Given the movement's contemporary nature and scholarly significance, new studies continue to emerge. The following section aims to provide a snapshot of the literature on OCLP and the Umbrella Movement at of the time writing. The majority of scholarly literature surrounding the Umbrella Movement has focused on the role of the media in mobilizing supporters and protesters. Lim (2014) focused on the aesthetic productions by protesters on-site as methods of participation and mobilization, while Chow (2015) articulates a power imbalance within the media from his lived experiences protesting versus media accounts of the movement. Some scholars (Lee and Chan, 2016; Lee So and Leung, 2015) have focused on the role of social media in mobilizing the movement, while others examined the role of more traditional forms of media such as newspapers (Bhatia, 2015) and local television broadcasts (Tang, 2015). Lee and Ting (2015) focused specifically on how the student group, Scholarism, was able to mobilize supporters through both traditional and 
social media. While the role of framing is relevant to all existing studies, it has never been interrogated specifically in existing literature on the movement. Thus, my research aims to examine what frames exist, how they emerge, how audiences accept these frames, and the gaps audience comments fill in relation to mainstream news discourses.

The Umbrella Movement produced a rich array of protest art and symbols in online and offline public spaces. Lim (2014) argues that these aesthetic productions (protest art, images of the protests, and symbols developed through the protest) are effective in mobilizing influence and encouraging protest participation. At the same time, authorities in Beijing were also able to utilise images and infographics to dissuade the public from joining the movement by emphasizing the illegality of occupying. Even though the movement was not deemed as successful in reaching its main objective to solidify universal suffrage in Hong Kong, Lim (2014) asserts that the movement is symbolic in itself by generating a "soft power persuasion" that has created more awareness on issues of international suffrage locally and internationally (p. 97).

As an active participant of the Umbrella Movement for 79 days, who experienced police violence at the protest site and was detained by authorities, Chow (2015) aimed to reveal the "extreme imbalance of power" between the Central authority and protesters through a discourse analysis (p. 484). Chow's (2015) findings suggest that members of authority were able to capture more attention in mass media. Sources and messages from the PRC were able to spread more effortlessly and were widely disseminated in comparison to voices from protesters (Chow, 2015). Recognizing his personal bias and 
resentment to the police, Chow (2015) asserts he maintained objectivity and the public articles from his research are all open to inspection by others.

The Umbrella Movement spread widely throughout social media. Lee and Chan's (2016) work examined the relationship between individuals' online activity in relation to their participation in the movement offline. Their findings revealed that participants who were more engaged in digital media activities (such as posting comments and sharing posts on Facebook) were more involved in the movement by either spending prolonged time at the protest sites, being active on the frontline or volunteering at help stations, and mobilizing new supporters (Lee and Chan, 2016). Online activity also revealed supporters using their collective efforts to dispel rumours that aimed to delegitimize the movement to regain public credibility and support, as well as build and maintain momentum for the Umbrella Movement (Lee and Chan, 2016). At the same time, Chan and Lee's (2016) research revealed that protesters were also using social media to combat messages produced by the state. Their findings also found a link between news consumption over social media and attitudes with authority. Individuals who consumed political news through social media were more likely to support the movement, but were also found to have more unfavourable attitudes with political authorities, such as the HKSAR government, police, and the Central government of Beijing. Examining the movement from a discourse-oriented analytical framework, Bhatia (2015) reveals how the movement was constructed through two months of news coverage in South China Morning Post. Bhatia's (2015) analysis reveals how key actors, conflicts, and events of the Umbrella Movement were categorized through what she defines as three "frameworks". These frameworks are shaped by discourses that form written 
accounts of reality. The three frameworks include the Student versus Occupier, the "Key Movement", and the "mini-Tiananmen". While Bhatia's (2015) research covers the entire span of the movement from the student boycotts to the first week of December, my research focuses on the period between the NPCSC's decision and the peak of the "Key Movement", which I define in my research as the Key Event (the first night of occupation on September 28, 2014 that ignited conflict between protesters and police). While Bhatia's (2015) research categorizes the Key Movement as a series of events, I use the term Key Event to define the conflict that catalyzed the rest of the movement and gave the Umbrella Movement its symbolic name. The frameworks that Bhatia (2015) outlined provided a basis for my research when seeking frames and themes deductively.

Further analyzing the events that unfolded on the night of the Key Event when tear gas was released on protesters, Tang (2015) studied effects of the event's portrayal on television news reports in mobilizing protesters. When police released pepper spray and tear gas among protesters, thousands of Hong Kong residents rushed down to the Central district to support the movement. An on-site survey at the occupation area was conducted and revealed that individuals who joined after seeing the images on television were considered "amateur protesters", characterized as individuals who were less likely to support any political parties and have a weaker sense of belonging in Hong Kong (Tang, 2015). The study also suggests that individuals who joined the movement used the television as a source for updated information (Tang, 2015). Social media was deemed a better source for gaining immediate information, but the images on television still played a role in attracting supporters (Tang, 2015). Tang's (2015) study demonstrates how attitudes and support for protests can be mediated through television and social media. 
These effects are more immediate and affect the local community to help support a movement within proximity.

Focusing specifically on members of Scholarism, one of the leading student organizations of the movement, Lee and Ting (2015) study the group as "agents of mediatisation". Their research focuses on the protesters using media logic to mobilize their movement rather than focusing on the role of social media or media in general as the leading influencers. Members of Scholarism were experts in influencing traditional, institutionalized media to their advantage. Students were able to connect with journalists on WhatsApp groups (a wireless messaging application) to deliver information that reflected their own views and aligned with their objectives, wrote press releases and held press conferences, as well as organized pseudo events to attract media attention (Lee and Ting, 2015). In the case of Scholarism, they were not only able to generate thousands of likes and shares on Facebook, but they also mobilized thousands of students onto the streets, captured international headlines, and influenced media outlets to report stories from their perspective. Acknowledging the practices protesters have taken in acquiring media attention demonstrates how protesters have greater ability to control how their image is portrayed over traditional mainstream media. Students' abilities to attract mainstream media attention lend insight to how the news frames from this movement were developed.

\subsection{Research Significance}

The majority of existing literature on the movement has focused on media depictions of the movement locally in Hong Kong or from the perspective of the 
protesters. There are also no existing studies that focus exclusively on how the movement was framed by multiple mainstream media sources. Explaining how the movement was framed by one news source provides one snapshot of the movement in one perspective, while this research aims to compare the movement's coverage across multiple news sources. Also, as studies focused mainly on the protesters' ability to mobilize protesters through media, little studies examine the other side of non-supporters. While local media reports have suggested the movement was widely accepted by society in Hong Kong, my research suggests otherwise. Examining the comment sections of each news article allows for new perspectives to be shared that do not necessarily align with mainstream media coverage. This research is motivated by these questions: How is the Umbrella Movement framed among three national online news platforms and what are the readers saying? These questions allow me to further interrogate the relationship between framing and social movements in online mainstream news and the types of audience responses generated from their frames. As existing literature has focused on depictions of the movement from dominant actors, my research also aims to unravel the discourses produced by the readers to reveal alternative perspectives on the movement and in turn, produce a greater understanding of the Umbrella Movement.

\subsection{Organizational Framework of Thesis}

The current chapter introduces the Umbrella Movement as a significant case to study framing and social movements due to its spontaneous emergence over mainstream news. In order to understand why the protest occurred, this chapter provided a condensed background on the key actors and events that motivated the current movement. While the 
movement is still ongoing, this chapter has also provided a snapshot of existing literature on the Umbrella Movement and the contributions of my research to this topic.

Chapter Two introduces framing as the theoretical framework anchoring this research. A literature review on the role of framing and social movements are provided, explaining how framing can both benefit and restrain a movement. The value of studying audience responses in the comments are also discussed, as well as existing literature on scholars that have implemented framing analysis from audience responses to mainstream media. This study's methodological process and corpus are also further outlined in this chapter.

Chapter Three situates the Umbrella Movement in Hong Kong's historical and socio-political context. As the introduction explained the more immediate events that led to the Umbrella Movement, this chapter demonstrates how the movement is a product of historical events, originated from years of struggle since the Handover when Hong Kong was returned back to China from Britain. This history will provide explanations to why the people of Hong Kong are currently dissatisfied with the Central government and why the route to democratization is important for Hongkongers.

In Chapter Four, key findings from news discourses are revealed to provide both causal frames and micro-frames that are directly related to the movement, as well as three macro-frames that stem from deeper societal and cultural ideologies: (a) Democracy as Remedy, (b) Tiananmen 2.0, and (c) Protesters as Manipulation. How these frames were 
built and how they differ cross-nationally will be further explored and discussed in this chapter.

Corresponding to the frames constructed from news discourse, key findings from audience responses in user comments are presented in Chapter Five. These findings reveal which frames audiences support or reject. News frames that were not supported generated more critical commentary that extended the conversation and led to greater discussions. These discourses produced more insights to the movement and the evolving role of news framing in the online space.

Chapter Six concludes the key findings of my research, its implications, as well as its limitations. Recommendations for future research are proposed to encourage more scholarly work on cross-national framing research and qualitative analysis of user comments when studying news framing. 


\section{Chapter: Legitimizing Social Reality through Framing}

Frames are important in everyday life as they allow individuals to organize their thoughts and processes information more efficiently. These everyday frames are what Goffman (1974) coins as "schemata of interpretation" that allow individuals "to locate, perceive, identify, and label a seemingly infinite number of concrete occurrences defined in its terms" (p. 21). Schemas help organize existing information, but also allow individuals to process new information more easily (Goffman, 1974). In order to experience and make sense of the world, our mind generates individual realities that are (re)constructed by the social world (Kant, 1970). Thus, individuals experience different perceptions of reality (Berger and Luckmann ,1966). Subjective reality is the socially constructed reality individuals experience, versus objective reality, which is seen as the "real world" (Berger and Luckmann, 1966). Van den Bulck (1999) asserts that this distinction of reality can only be made theoretically, as individuals living in their subjective realities cannot measure the differences of these realities. However, individuals often seek to legitimate their subjective realities by "objectifying" it (Bhatia, 2015). A common way to seek legitimacy in an individual's subjective reality is to know what the majority of society consents to (Berger and Luckmann, 1966), which is where the role of media becomes important for individuals to validate their subjective realities in the "objective" world. While mass media are not the only way to objectify particular representations of reality, their role in disseminating information in society is nonetheless important. Media frames are "largely unspoken and unacknowledged, organize the world both for journalists who report it, and in some degree, for us to rely on their reports" 
(Gitlin, 1980, p. 7). The process of creating reality becomes a communicative process, in which framing in mass media contributes to the social construction of reality that audiences rely on to be informed of their own. Frames therefore facilitate the interpretation of real world events and at the same time, objectify these interpretations for the validation of subjective realities.

\subsection{Framing of Social Movements: Literature Review and Key Concepts}

There is a significant body of work by communication scholars that examines the relationship between media framing and social movements. Due to its ability to shape perceptions of social reality, news frames have been studied widely in communication studies. How news is framed in the media is important because audiences with no direct experience of the events will depend on media accounts to stay informed and make rational decisions (Entman, 1991). Acknowledging that framing practices may not necessarily be intentional, my research adopts Entman's (1993) definition of framing as a process that selects "some aspects of a perceived reality and make them more salient in a communicating text, in such a way as to promote a particular problem definition, causal interpretation, moral evaluation, and/or treatment recommendation of the item described" (p. 52). When framing is undetected or unquestioned, news accounts of events can be perceived to be a complete and accurate representation of reality, rather than a smaller piece of actuality.

Social movements share a collective identity and are organized to produce collective actions to create or resist change through a variety of strategies (West and Blumberg, 1991). Collective actions typically emerge as a reaction to repressive 
conditions found in the political or social system and are intended to mobilize the public to remedy the cause (Zald and McCarthy, 1987). According to McAdam, McCarthy, and Zald (1996), social movements require three fundamental components to develop and grow: mobilizing structures, opportunity structures, and framing processes. Mobilizing structures are at the forefront, as they are instruments that allow protesters to form a collective and take action. Opportunity structures involve a specific context or circumstance that allows a social movement to take place. Framing processes are crucial to social movements as organizers need to present their cause in alignment with the shared values of the groups they wish to attract so their cause is deemed worthy and significant (McAdam, McCarthy, and Zald, 1996). While mobilizing structures are controllable by protesters and organizers initiating action, opportunity structures can be more difficult to plan and predict. Framing processes lay in between, as protesters are able to generate and disseminate their own frames while competing with others that are also constructing their representations to the public. The reliance on others to generate frames with favourable representations of the social movement becomes important for its success.

Social movements are able to generate "collective action frames" (Gamson, 1992) that are "action-oriented sets of beliefs and meanings that inspire and legitimate the activities and campaigns of a social movement organization" (Benford and Snow, 2000, p. 614). According to Snow and Benford (1988), there are often two components to social movement frames: diagnostic and prognostic. Diagnostic frames pinpoint the issue at stake and prognostic frames suggest what can be done to solve the issue (Snow and Benford, 1988). In order for collective action frames to be successful, there needs to be 
an underlying belief that the problem can be solved through collective efforts of social change. However, there is a "fundamental asymmetry" between mainstream media outlets and social movements, as media organizations have more power when it comes to transmitting their messages (Gamson and Wolfsfeld, 1993, p. 115). While organizers of social movements now have greater control of their messages through social media and other methods of citizen journalism, mainstream media still reach greater audiences. A great deal of agency is granted to media outlets and the journalists that report on news. Journalists have the ability to emphasize or exclude certain information to shape the discourses revealed in the news and the stories they produce, ultimately structuring the way audiences receive information. Mass media act as containers for public discourses (Gamson, 1998), but they also allow political actors to maintain their credibility in the eyes of the public (Chow, 2015). Although the media often include stories that reflect existing attitudes and beliefs, they can also act as a public relations platform for authorities to influence their own agenda.

Scholars (Gottlieb, 2015; Di Cicco, 2010; Chan and Lee, 1984) have identified that news organizations have a tendency to delegitimize protests by ignoring the core concerns of the movement, known as the "protest paradigm". Instead of focusing on the main issues surrounding the movement, news organizations tend to center stories around violence and conflict (Boyle, McLeod, and Armstrong, 2012). Typically, coverage of social movements is not considered "newsworthy" until they have mobilized large masses, or if there is conflict or controversy involved (Gottlieb, 2015). Organizers and participants of social movements often face the "protester dilemma", where news outlets may not cover their movement unless protesters engage in conflict or drama (Boyle et al., 
2012, p. 130). These actions deem the protest to be more "newsworthy", but on the other hand, these same actions often delegitimize the protesters.

The best scenario for social movement organizations would be for news outlets and journalists to cover the events in favour of the protesters' and movement's preferred representation to legitimize their actions. This is defined by Snow, Rochford, Worden, and Benford (1986) as the frame alignment process. Frame alignment is referred to as "the linkage of individual and SMO [social movement organizations] interpretive orientations, such that some individual interests, values, and beliefs and SMO activities, goals, and ideology are congruent and complementary" (Snow et al., 1986, p. 464). Snow et al. (1986) outlines four types of frame alignment processes: frame bridging, frame amplification, frame extension, and frame transformation. Frame bridging is when two or more ideologically consistent but structurally unconnected frames are linked in regards to a particular issue (Snow et al., 1986). The bridging process can occur at an individual level or organizational level, such as when an individual expresses similar beliefs with the SMO's concerns. These are usually individuals or groups of individuals who have common grievances but have yet to mobilize and take action with their concerns. Frame amplification involves the reinforcement or revitalization of a frame, consisting of both value amplification and belief amplification (Snow et al., 1986). Value amplification continues to reinforce the importance of the movement's goals with the individuals it aims to recruit as supporters, while belief amplification communicates the efficacy of collective action in achieving the SMO's goals. In order to gain more supporters, frame extension is a practice used to expand beyond the SMO's primary framework to include messages that other groups of society can also agree with. Lastly, frame transformation 
may need to occur when the primary framework is no longer effective in generating collective action or resonating with supporters. Thus, SMOs may need to engage in reframing and transform the existing frame.

\subsection{Cross-National Framing}

In contrast to objective reality, subjective realities are also shaped by the ideologies of society. This may provide an explanation to why news reports on one event or issue may differ cross-nationally. The way different organizations frame the news is "consistent with the values embedded in a community, society, or a nation on a macro level" (Kwon and Moon, 2009, p. 271). The majority of framing research is conducted within national boundaries, instead of examining frames at cross-national macro level (de Vreese, Peter and Semetko, 2001). Looking at cross-national perspectives is important because each nation has dominant societal values that are "unconsciously instilled in news discourse", known as “enduring values" (Kwon and Moon, 2009, p. 271; Gans, 1979, p. 42). Nossek (2004) argues that national collectivistic storytelling in journalism is inversely related with professional objectivity. Collectivistic storytelling occurs when international news is seen as "our" news, versus an issue that is "their" news is produced with a professional objective viewpoint (Nossek, 2004). Kwon and Moon (2009) also attest that collectivistic storytelling occurs more in international news coverage, as professional narratives often turn into cultural narratives. As media institutions are shaped in the socio-political environment in which they operate (McQuail, 1994), journalistic practices are developed through national cultures as well (Kwon and Moon, 2009). This thesis contributes to the body of cross-national framing research by 
examining the possibility of perceived national "enduring values" making an appearance within online news reports. Since online boundaries are fluid, many news organizations may shift their ideologies to appeal to broader international audiences. By studying the discourses produced by three national online news sources on the Umbrella Movement, this research provides additional insights to practices of collectivistic storytelling in an online news environment.

\subsection{Framing and Public Discourse}

Although there is comprehensive research on media framing, there has been limited research on the framing processes of public discourses. According to Gamson (1992) and Price (1988), "framing research should go beyond the impact of individual cognition and highlight the macro aspect of the interplay between media frames and the frames of a group of people, defined as the public" (Kwon and Moon, 2009, p. 274). The public domain is the middle ground between media representation and an individual audience's perception (Price, 1988). The interactivity of online channels allows for nonprofessional opinions to be shared over the Internet. While newspapers traditionally feature sections such as "Letters to the Editors", online comment sections allow immediate interaction between commenters and the content. Online news channels adopted from traditional newspapers have the ability for more immediate audience feedback through the comment section, providing an interactive space for public discourse. These channels provide more opportunities to analyze public discourses 
surrounding a movement, its reception of the news article, and new perspectives that may be missing in professional channels.

As audiences, readers are constantly engaged in the process of "making things mean" (Hall, 1982, p. 64). As news frames produce a fixed product made for audience consumption, there is never one true fixed meaning that consumers will interpret (Hall, 1999). Similarly, this is also why individuals' subjective realities differ, as they are engaged in different processes of decoding information. Comment sections provide opportunities to dissect the process of decoding and reception to news content. Many of these studies implemented quantitative content analysis in order to scan keywords from comments that correlates with content from mainstream news. Holton, Lee, and Coleman's (2014) study wished to find an association between news frames and audience responses to health articles. Their study revealed that audiences do not necessarily repeat news frames within the comments, as audience frames did not align with news frames. This means that audiences are not simply accepting the dominant position held in news frames, but rather holding negotiating or oppositional positions (Hall, 1973).

A number of scholars have studied news comment sections as novel communicative spaces, typically through the lens of digital democracy and its potential to foster a digital public sphere, aligned with Habermas' (1962/1989) ideals of deliberative democracy (Dahlberg, 2011; Toepfl and Piwoni, 2015; Lee, 2012; Lee and Jang, 2010; Ruiz et al., 2011). Online editions of mainstream newspapers open up opportunities for public deliberation to emerge (Manosevitch and Walker, 2009). These comment spaces provide readers the ability to critique the news and add their own opinions, while responding to others. In turn, these comment spaces can generate perceptions of public 
opinions, but also influence readers' own opinions (Lee, 2012). Other studies (Coe, Kenski, and Rains, 2014) studied the nature of uncivil commenters, as online comment sections are often discounted for their value in research due to potential uncivil nature of online environments. However, Coe, Kenski, and Rains' (2014) study reveal that uncivil commenters are often more likely to use evidence to support their claims, as well as produce stronger reactions from others. However, the topic of the article and sources used within the articles can also influence the amount of incivility that may occur (Coe et al., 2014). Comments from news sites were seen to exhibit more a deliberative quality than comments from Facebook users (Rowe, 2015). Ruiz et al. (2011) also noted that comment sections of online news in Anglo-American countries had greater deliberative quality than others. Overall, expanding reader involvement in mainstream journalism is understood as a positive transformation that can potentially strengthen democracy by creating more deliberative spaces for rational communication (Dahlberg, 2011).

\subsection{Methodology}

My research situates a news framing analysis within a discourse analysis. Although content analysis the most common approach to news framing analysis, my study adopts a more inductive qualitative approach. Existing scholarly research has not explored news framing of the Umbrella Movement on a cross-national level. Thus, I am taking an exploratory inductive approach that is concerned with the frame building process to dissect the content of the frames and categorize the dominant frames that emerge from each news platform. Identifying dominant media frames often requires a discourse analysis so that news texts can be conceptualized into "empirically 
operationalizable dimensions - syntactical script, thematic, and rhetorical structures - so that the evidence of the news media's framing of issues in news texts may be gathered" (Pan and Kosicki, 1993, p. 55). How these frames are produced is important because they "have the effect of constructing some of the limits and parameters within which decodings will operate" (Hall, 1980, p. 135). Although my research is not concerned with the cognitive effects of news framing on audiences, my research does situate news framing as a platform for discussion through user comments. News frames articulate the values and perceived factual evidence to highlight key issues and provide insight on the types of discourse generated by them. A dual discourse analysis of news media and comments by online readers will allow me to analyze both the content and responses at the same time. Morley (1980) suggests, "The analysis of content ... gives us clues to what might be effective in it. The analysis of responses to it enables us to check those clues" (p. 3). Studying the text and its rhetorical structures will lend insight to how certain types of media messages produce certain kinds of discourse.

The texts composing my corpus are treated as three representative national news organizations in Hong Kong, mainland China, and the United States. Justification of these news organizations is further elaborated in the following section. My research incorporates an analysis of excerpts of the total text, rather than coding entire individual articles. This is because I am focusing on what and how dominant frames are produced at a micro and macro-level from a body of discourse. Micro-level frames are constructed on a smaller level that deals with specific frames of a certain issue, such as how the protesters were depicted in the Umbrella Movement. Macro-level frames are situated on a broader level that demonstrates "how frames are connected to the surrounding culture" 
(Reese, 2010, p. 21), such as the treatment of democracy as a remedy of all social problems.

Due to the exploratory nature of my research, I have utilized Van Gorp's (2010) suggested strategies to minimize researcher subjectivity in my analysis. When identifying frames, Van Gorp (2010) advises researchers to construct a frame package, described as "an integrated structure of framing devices and a logical chain of reasoning devices that demonstrates how the frame functions to represent a certain issue" (p. 91). Framing devices are described as the "manifest elements in a text that function as demonstrable indicators of the frame", such as the use of historical examples, textual depictions, metaphors, lines of reasoning, contrasts, lexical choices, sources, and appeals that construct rhetoric (Van Gorp, 2010, p. 91). Reasoning devices provide a line of causal reasoning that are evoked with an issue is associated to a particular frame (Van Gorp, 2010). Reasoning devices do not need to be implicit within the text, as they are developed by causal inferences. Figure 1 demonstrates how Van Gorp's (2014) strategies have been applied in three selected examples. I have interpreted the frame package as a process of frame building. Findings revealed in Chapter Four are dedicated to identifying what frames are present in news discourses and how they are developed through framing devices and reasoning devices. While it is possible that a variety of overlapping frames can emerge across each news source within the entire corpus, this study only reports on 
the key dominant frames that appear within the news reports produced by each individual news outlet: SCMP, WP, and GT.

\subsubsection{Corpus}

News articles on the Umbrella Movement from the South China Morning Post

International Edition (SCMP), the Washington Post (WP), and Global Times (GT) were 
Figure 1: Exemplifying the Elements in Constructing a Frame Package 


\begin{tabular}{|c|c|c|c|}
\hline Macro Frames & Source Text & Framing Devices & Reasoning Devices \\
\hline $\begin{array}{l}\text { Democracy as } \\
\text { Remedy } \\
\text { (SCMP) }\end{array}$ & $\begin{array}{l}\text { "Sui Wai-keung, 31, delivery man: "Sure, } \\
\text { I'm worried about how the protests will } \\
\text { affect the local economy, but if all you do is } \\
\text { earn money and don't fight for democracy, } \\
\text { then you're basically a robot. That's not } \\
\text { going to help the next generation." }\end{array}$ & $\begin{array}{l}\text { Use of quotes from bystanders as a } \\
\text { representation of real sentiments } \\
\text { towards the movement. Contrast } \\
\text { the democracy movement with } \\
\text { economic concerns. Real people } \\
\text { care for the future, while robots } \\
\text { earn money. }\end{array}$ & $\begin{array}{l}\text { Individuals who care more } \\
\text { about money than this } \\
\text { movement are heartless. The } \\
\text { fight for democracy is more } \\
\text { important than temporary } \\
\text { hiccups in Hong Kong's } \\
\text { economy. Hongkongers care } \\
\text { more about democracy. }\end{array}$ \\
\hline $\begin{array}{c}\text { Tiananmen } 2.0 \\
\text { (WP) }\end{array}$ & $\begin{array}{l}\text { "...But it's also difficult not to remember } \\
\text { the similar mass demonstrates that filled } \\
\text { Beijing's Tiananmen Square } 25 \text { years ago } \\
\text { and how those ended." }\end{array}$ & $\begin{array}{l}\text { Use of Tiananmen as a historical } \\
\text { example, suggesting that history is } \\
\text { repeating itself. }\end{array}$ & $\begin{array}{l}\text { Fear of China suppressing the } \\
\text { protests with force, mirroring } \\
\text { similar outcomes from the } \\
\text { Tiananmen Square Massacre of } \\
1989 .\end{array}$ \\
\hline $\begin{array}{l}\text { Protesters as } \\
\text { Manipulation } \\
\text { (GT) }\end{array}$ & $\begin{array}{l}\text { "Here in Russia, the umbrella-wielding } \\
\text { demonstrators of Hong Kong are being } \\
\text { presented as pawns in a Western plot to } \\
\text { foment instability in yet another one of } \\
\text { Moscow's allies... Russian media reports } \\
\text { have discerned in Hong Kong an American } \\
\text { "recipe" for upsetting governments in the } \\
\text { style of the "color revolutions" that took } \\
\text { place in former Soviet states over the past } \\
\text { decade." }\end{array}$ & $\begin{array}{l}\text { Use of speculation with little } \\
\text { evidence to generate conspiracy. } \\
\text { Practicing personal victimization } \\
\text { and attributing a culprit. }\end{array}$ & $\begin{array}{l}\text { The protesters are not protesting } \\
\text { on their own accord, but rather } \\
\text { manipulated in an international } \\
\text { game as "pawns". United States } \\
\text { is using its history with Russia } \\
\text { to now target China. }\end{array}$ \\
\hline
\end{tabular}


chosen through purposive sampling strategies. The corpus contains both professionally published and more naturally occurring discourse on the Umbrella Movement. These three news outlets were chosen due to their large online and offline presence as mainstream news organizations, and all contain platforms for users to contribute. These sources have also been chosen because each may be said to represent dominant perspectives within its country.

South China Morning Post (SCMP) is a newspaper from Hong Kong that tends to have a more relatively neutral stance on the government. According to a survey conducted in 2010 by the Chinese University of Hong Kong, SCMP is considered the most credible news source in Hong Kong (Bhatia, 2015). Approximately 90 percent of SCMP's audience was based in Hong Kong, but after recent marketing initiatives, its international readership has grown significantly, where 60 percent of audiences are from North America, Europe, and Asia Pacific (Western iMedia, 2015). SCMP online garners fifteen million monthly page views with a reader demographic consisting of 60 percent male, 40 percent female, with 67 percent having university education or higher. Although SCMP has a pay-wall after a limited amount of articles, I still chose to use this news source due to its media prominence and heightened user status in Hong Kong that also allows users to contribute in the comments after signing up for an account.

The Washington Post (WP) provides news from the United States with a more liberal slant and tends to concentrate more heavily on national political issues. Although WP was originally a regional newspaper, its expansion online has driven its readership to beating New York Times in October 2015, with 66.9 million unique visitors (Valinsky, 2015), making it one of the most popular online newspapers in the United States. Its 
reader demographic consists of 46 percent female and 54 percent male, with 51 percent likely to have a college degree education or higher (Washington Post Media, 2013). WP was chosen among other popular Western online news outlets because non-subscribers were able to comment as well, and users are not limited by a pay-wall.

Global Times (GT) is an extended English version of the People's Daily, a highly conservative newspaper whose publications come from the Communist Party of China (CPC). GT provides world news with a more populist function to engage its readers, but positions nationalism highly in its content (Larson, 2011). It is the third-largest newspaper in China, with a daily print readership of 2.4 million and web readership of 10 million (Larson, 2011). GT also has a comment section for viewers to sign up freely and join the discussion with limited barriers and there is no pay-wall.

News articles collected from SCMP, WP, and GT ranged from August 29, 2014 to October 10, 2014, searched using keywords: “Umbrella Revolution”, “Umbrella Movement", "Hong Kong Protests", and "Occupy Central" in accordance to different news platforms. August 31, 2014 was when the NPCSC's decision was released, which is why the article search began from August 29, 2014. There was limited media coverage until the umbrella and tear gas confrontation occurred between protesters and police in Hong Kong's Central district on September 28, 2014. This date, hereby referred to as the Key Event, ignited the Umbrella Movement to unfold throughout the following weeks. This pivotal moment in the movement marked the development of the news frames that emerged, which is why the corpus covers the first 12 days of the movement after the Key 
Event. Within this scope, a total of 89 news articles were coded and analyzed (52 from SCMP, 16 from WP, and 21 from GT), as well as 6, 212 user comments.

\subsubsection{Coding}

Due to the exploratory nature of this study, inductive methods were primarily applied throughout the coding process. After the initial open coding stage, codes were imported into two categories: micro-level frames and macro-level frames. Micro-frames identified causal frames (reasons attributed to the protests) and the Umbrella versus Tear Gas frame that describes issues specific to this movement. The macro-leveled thematic frames that illustrate a broader narrative on the issue's effects towards certain aspects of society are: (a) Democracy as Remedy, (b) Tiananmen 2.0, and (c) Protesters as Manipulation. Evidence and codes used to organize these frames will be discussed in Chapter Four. The coding process for audience comments involved both inductive and deductive methods. Deductively, I drew connections from user comments that correspond to the three macro-leveled thematic frames. Inductive coding methods were in place for comments that did not pertain to the three outlined thematic frames. These comments were organized in relation to responses to dominant news frames and responses to the news source's coverage in general. Discourses from user comments are presented in the findings of Chapter Four. 


\section{Chapter: Contextualizing the Umbrella Movement through History}

The Umbrella Revolution that emerged across international news headlines from the events following the night of September 28, 2014 was not constructed as quickly as its name was conceived. The movement is part of a greater history of Hong Kong's prodemocracy movements that are deeply rooted in its people and the city, influenced by the "One Country, Two Systems" regime that ties the region politically with mainland China. This system has not only changed how the city operates on an institutional level, but has also generated a discerned struggle Hong Kong people have with their sense of national identity. To understand news and audience discourses surrounding the Umbrella Movement, this chapter provides a description of Hong Kong's socio-political history, revealing the underlying struggles and factors that motivated and continue to influence Hong Kong's pro-democracy movements. At the same time, Hong Kong's history can also explain the types of discourses that emerge from mainstream news platforms, as current discourses and news frames emerge from historical events and knowledge.

\section{1 “One Country, Two Systems"}

Hong Kong Island acted as a trading chip China was forced to forfeit in 1842 after its loss to Britain during the first Opium War of 1839 under the Treaty of Nanking. In 1898, the New Territories and its 235 islands were then leased to Britain to use as trade port harbours for the following 99 years. As the terms of the treaty were coming to an end, China demanded for Hong Kong's return. During this time, there was an immediate urge for the British government to democratize Hong Kong's political system before the 
city was returned back to China. Despite Britain's efforts to standardize democratic reform for most of their colonies, their plans were halted in 1952 as the civil war in China led to Communist control that threatened to take Hong Kong by force, revealed by more recent documents from the British National Archives (Guilford, 2014). Pressured by China's unwillingness for Hong Kong's progression towards democratization and avoiding threats of hostile takeover by the Communists, the British government was forced to negotiate with China. This resulted in the 1984 Sino-British Joint Declaration that discussed the terms in which Hong Kong would be returned back to the People's Republic of China.

During the 156 years under British control, Hong Kong was granted the freedom of speech and freedom of press, even without democratic rule. Thus, when early news of Hong Kong being returned back to China arose in the 1990s, the people of Hong Kong were afraid they would no longer be granted the same rights they have been accustomed to, since China's central government operates under the rule of one party: the Communist Party of China (CPC). The terms under the Sino-British Joint Declaration were greatly dictated by China, as the British had few bargaining powers (Ortmann, 2015). While China strictly opposed full democracy, Hong Kong's last Governor, Chris Patten, managed to negotiate terms that enabled Hong Kong to operate as a Special Administrative Region dictated by the Basic Law. Under the Basic Law, Hong Kong would operate under Deng Xiaoping's "One Country, Two Systems" regime for 50 years, the same principle currently implemented in Macau and theoretically with Taiwan. Under 
this agreement, Hong Kong was returned to China on July 1, 1997, an event commonly referred to as the Handover (Gargan, 1997).

\subsection{Brewing Dissatisfaction under Hong Kong's Political Structure}

Hong Kong's status as a Special Administrative Region (SAR) allows the city to be a part of China while operating under its own government that grants its citizens

freedom of speech, press, and other forms of freedom in comparison to the rest of China. While the Basic Law assures that the HKSAR has a high degree of autonomy, Cheng (2014) asserts that "the people of Hong Kong have often been reminded by Chinese officials that they have to think more of 'one country' than 'two systems", limiting their degree of autonomy (p. 3). While Hong Kong is governed by its own Chief Executive, his role is largely perceived by its people as a puppet of the government officials in Beijing (Cheng, 2014). The current system that governs HKSAR is seen as a "black box regime" with very little transparency outside of its executive-led team (Garrett, 2015, p. 65). The executive team that leads Hong Kong (the Chief Executive, his cabinet, and executive council) are all appointed by Beijing. The legislature plays a limited role because the Chief Executive must approve of proposals being passed (Cheng, 2014). Political parties also have a fairly limited role in Hong Kong's political system, granting significant power to the Chief Executive. This becomes problematic for the people of Hong Kong, as they feel their sense of autonomy is limited by the political system itself.

Prior to 1997, Hong Kong was characterized by its booming economic growth as a capitalist society with a politically apathetic citizenry (Mushkat, 1992; Lee and Chan, 2011; Cheng, 2014). There was general satisfaction with the British government's performance during colonial rule (Cheng, 2014). In contrast, the people of Hong Kong 
have expressed more discontent with the current and previous HKSAR administrations after the Handover. In between C.H. Tung, Donald Tsang, and the current C.Y. Leung administrations, there has been a rise in protests. Protesters have been depicted carrying old colonial flags to suggest their discontent with governance under China and preference for British rule (Cheng, 2014). The number of votes C.Y. Leung received from the Election Committee to secure his current position was only 689 out of the 1,200 votes casted, rendering him an easy target for citizen mockery of Hong Kong's electoral process (Chan, 2014). As dissatisfaction with the government grows, demands for changes to the election process emerge, as citizens want to exert greater control over who is elected to be their Chief Executive.

\subsection{Plans for Electoral Reform under Article 45's Ambiguity}

Article 45 of the Basic Law contains the Central government's promise to allow Hong Kong citizens to eventually elect their own Chief Executive through the means of universal suffrage. The terms under Article 45 dictate that:

The Chief Executive of the Hong Kong Special Administrative Region shall be selected by election or through consultations held locally and be appointed by the Central People's Government.

The method for selecting the Chief Executive shall be specified in the light of the actual situation in the Hong Kong Special Administrative Region and in accordance with the principle of gradual and orderly progress. The ultimate aim is the selection of the Chief Executive by universal suffrage upon 
nomination by a broadly representative nominating committee in accordance with democratic procedures.

(The Basic Law of the Hong Kong Special Administrative Region of the People's Republic of China, 2015)

However, the government has not defined what constitutes a "democratic procedure" or what "universal suffrage" dictates. At the same time, a "broadly representative nominating committee" is only representative of 800 members from key sectors in Hong Kong, such as the "industrial, commercial and financial sectors" and "the professions" (The Basic Law of the HKSAR, 2015). The election committee of 800 to 1200 members is not an adequate representation of Hong Kong's current population of 7.3 million.

In 2010, the National People's Congress Standing Committee (NPCSC) in Beijing promised that the people of Hong Kong could elect their own Chief Executive by 2017 through universal suffrage as well as the seats of the legislature by 2020 with the same methods (Chan, 2014). Instead, the government continued to backpedal against its own terms. On August 31, 2014, the NPCSC announced that candidates for Chief Executive would be chosen by a nomination committee in Beijing that screens candidates before allowing the people of Hong Kong to vote through "universal suffrage". This means that citizens of Hong Kong are not able to nominate their own candidates, but rather vote amongst pre-selected candidates approved by Beijing. Thus, undermining the impact of direct elections and not giving Hong Kong citizens a fair choice for whom they wish to appoint as Chief Executive. This decision is what ultimately fuelled the student boycotts and members of OCLP to Occupy the Central financial district of Hong Kong during the Umbrella Movement. Hong Kong is facing a critical "political reform cliff”, as 2017 is seen as Hong Kong citizens' last opportunity to achieve universal suffrage (Lam, 2014). 
Professor Chan Kin-Man, one of the three leaders of OCLP, is afraid that if Hong Kong fails to introduce universal suffrage by 2017, "Hong Kong will fall into a deep quagmire" and deliberative democracy will never be introduced in Hong Kong by the Central government in Beijing (quoted in Lam, 2014).

\subsection{Social, Economic, and Cultural Changes in Hong Kong}

Post-Handover anxieties of governance under China and its role as a hegemonic force have affected the cultural, socio-economic, and political way of life in Hong Kong. Under colonial rule, Hong Kong experienced blossoming economic development under a laissez-faire policy. This created greater social mobility, giving the people of Hong Kong vast opportunities for economic growth, decreasing its wealth gap (Ortmann, 2015). Existing tensions between the people of Hong Kong and mainland China can be identified by sentiments of economic inequality. Some of these tensions are the byproduct of negotiations prior to the Handover. In order to maintain political stability and foster Hong Kong's booming economic growth, the Chinese government aimed to please the business elite of Hong Kong. The elite, who had central control during an era characterized by laissez-faire policies, were assured that they would maintain their economic dominance (Ortmann, 2015). This short-term way of preserving stability during the Handover led to greater economic inequality. Power was in the hands of the business elite and the Chinese government, while Hong Kong citizen salaries could not keep up with the rising standards of living (Ortmann, 2015). This dramatic change in quality of 
life and limited upward mobility led many people of Hong Kong to question the legitimacy of the government and generated negative sentiments toward mainland China.

Prior to the Handover, 60 to 70 percent of the people of Hong Kong considered themselves to be in the society's middle-class, compared to the post-Handover period, where more youth are more likely to question whether or not they even belong in the middle class (Cheng, 2014). According to the United Nations Development Programme, Hong Kong's wealth gap was the widest among all Asian cities in 2008 and 2009 (Cheng, 2014). The percentage of the "poorest families" earning between HK $\$ 3,000$ to HK $\$ 6,000 \mathrm{HK}$ per month rose by 12 percent while the richest earning a median income of HK $\$ 80,900$ increased by 16 percent (Ming Pao, 2010 in Cheng, 2014). The number of "poor families" grew to 1.26 million (18.1 percent of the population) in 2010, with a median monthly income of HK $\$ 9,000$ (Ming Pao, 2010 in Cheng, 2014). The people of Hong Kong feel that they no longer have the same opportunities as before, with less advantageous living standards in the current post-Handover period. This dissatisfaction has led to an "erosion of their identification with the territory's political and economic systems" (Cheng, 2014, p. 9). While Hongkongers experienced an increase in quality of life under British colonial rule, they are experiencing less prosperity under ruling of the PRC.

Hong Kong citizens fall into what Flanagan (2014) calls a "peripatetic zone", where their lives are lived between two spaces generated a cultural divide, transitioning from colonial rule to its current system connected to mainland China. According to Liu (2015), "Hong Kong's national identity has been much influenced by tensions between oppositional cultural traditions and values" (p. 3). The identity of a "Hongkonger" is 
made up of "core values" such as freedom, the rule of law, and the rejection of communism (Garrett and Ho, 2014). Deng (2009) argues that Hong Kong's cultural and political differences with the mainland stem from the education curriculum in the colonial and post-colonial era, which deliberately avoided topics related to contemporary China. Instead, education programs focused on virtues of ancient China that were not persistent in modern China, leading to a vague sense of national identity (Liu, 2015). The Chinese identity they were taught was seen as abstract, as it was disconnected from a "tangible reality" (Luk, 1991, p. 668). This led to a perplexity of Hong Kong identity and a confusing understanding of mainland Chinese identities.

The people of Hong Kong see themselves as having a unique identity that is differentiated from mainland China, influenced by both the political structure of Hong Kong and their cultural upbringing. Hongkongers believe that the Central government threatens their identity, as they want to refrain from being "just another Chinese city" (Garrett, 2015). Mainland China is seen as a hegemonic force that aims to assimilate through its political rule and thereby, their threatening Hong Kong's personal and cultural identity. Examples of these sentiments toward mainland China can be observed in Hong Kong's support of the 2014 Taiwan Sunflower Movement, where Taiwanese identity was seen as threatened by "mainlandization" due to greater economic integration with China (Garrett, 2015). Hong Kong's fifth legislative election since the Handover in 2012 was also heavily focused on identity politics. "Only one issue mattered for the Legislative Council election ... resistance against mainland influence. Mobilization based on the fear of China - rather than issues related to society, democratization, economy, or any specific policy program - was the most effective campaign strategy" (Yep, 2012, quoted in 
Garrett and Ho, 2014). These examples suggest a consistent struggle between Hong Kong and mainland China, as there is a clear delineation between "Them" versus "Us".

\subsection{The Turning Point of Hong Kong's Pro-Democracy Movement}

One of the earliest and largest mass pro-democracy protests in Hong Kong occurred on May $21^{\text {st }}, 1989$, where 1.5 million protesters attended to sympathize with the Tiananmen Square student movement in Beijing. Imminent fears from the outcomes of the Tiananmen Square Massacre have influenced Hong Kong's political culture, as Hongkongers fear their freedom may be threatened as well (Chan, 2014). One of the city's largest protests after the Handover occurred on July 1, 2003. The protest consisted of 500,000 participants who rejected Article 23 of the Basic Law's anti-subversion law that would ultimately allow government officials to censor dissent from the press and shut down religious and political groups banned in the mainland. Lee and Chan (2011) argue that the July 1, 2003 protest is a watershed event that mobilized and awakened Hong Kong's pro-democracy movement. Article 23 was seen to "embody the tension that is inherent in the 'one country, two systems' model that governs Hong Kong's relationship with the mainland" (Petersen, 2005, p.1). According to on-site surveys conducted by Lee and Chan (2011), 82.3 percent of protesters "strongly agreed" that they were participating in the protest mainly due to dissatisfaction towards the performance of Hong Kong's government, rather than directly protesting Article 23. Dissatisfaction with 
the government continuously grew over the years since the Handover, but peaked during 2003 due to how the government was handling the SARS outbreak (Lee and Chan, 2011).

The unpredicted number of 500,000 participants shocked not only the government of Hong Kong, but also the protest organizers (Lee and Chan, 2011). Up until the events of 2003, Hong Kong citizens were seen as politically apathetic, ones more invested in private interests rather than collective demands (Lee and Chan, 2011). The victory and success of the July 1 protests defied this dated view of Hong Kong citizens. Hong Kong citizens now participate in yearly marches in the city on July 1, creating a "ritualistic protest" and igniting the pro-democracy movement in Hong Kong (Lee and Chan, 2011). Moreover, the event has reinvigorated the spirit of Hong Kong citizens to strive for quicker democratization in the city itself. Early signs demonstrate that the Umbrella Movement can also be seen as a pivotal event in Hong Kong's pro-democracy movement. Although it is too soon to tell, there have been reoccurring protesters on September 28 to commemorate the cause and to remind citizens of Hong Kong's desire to achieve democracy.

\subsection{Conclusion}

Hong Kong's current status as a Special Administrative Region is a product of historical tensions and struggles between the British and mainland China. Moving away from a colonial rule that granted greater freedoms to operating under China's current “one country, two systems" policy, the Handover marked a significant transition that affected the political, social, and cultural facets of Hong Kong. The years of discontent in Hong Kong society since the Handover has led to the critical development of Hong 
Kong's pro-democracy movement. This movement not only signifies the desire for democracy and greater upward social mobility, but also the necessity to maintain Hong Kong identity while minimizing the influence of mainland China. The Umbrella Movement is a manifestation of these key issues. The issues that stem from Hong Kong's history shape the subjective realities perceived by news media and experienced by audiences. Therefore, knowledge of the socio-political, economic, and cultural factors that influence the movement will lead to greater understanding of the discourses surrounding the Umbrella Movement. 


\section{Chapter: Finding Key News Frames}

This chapter reports key frames surrounding the Umbrella Movement from news discourse generated by the online editions of the South China Morning Post (SCMP), the Washington Post (WP), and Global Times (GT). Micro-level frames are first introduced to establish how this specific movement was framed at a certain point in time. The first micro-level frames are categorized as causal frames, which introduce and identify the reasons of outbursts that led to the Key Event on September 28, 2014, by the media. Another frame specific to this movement is the Umbrella versus Tear Gas frame, which illustrates the differential media reporting of the movement from all three news sources since the Key Event. This frame provides a baseline for the overall tone and attitude each news source has in its reporting. These individual stances are further dissected to reveal dominant macro-level frames from each news source. From SCMP, the Democracy as Remedy frame emerged. This frame suggests that democracy is the ultimate form of governance and will solve the current issues that are barraging Hong Kong society. The WP's panicked reaction towards China's possible violent treatment towards the protesters of the movement generated the Tiananmen 2.0 frame. Assuming that history will repeat itself, this frame suggests that support for the Umbrella Movement is needed in order to prevent China from harming the protesters of Hong Kong, as the government has previously during the 1989 Tiananmen Square incident. Lastly, GT heavily relied on delegitimizing the movement as unrepresentative of attitudes of all Hongkongers. In doing so, the frame Protesters and Manipulation emerged, as GT's coverage focused on silencing protesters that were challenging the status quo by undermining their influence 
as genuine. This chapter also leads a discussion of key findings on cross-national framing, as well as the relationship between framing processes and social movements in the case of the Umbrella Movement.

Figure 2: Distribution of Online News Articles

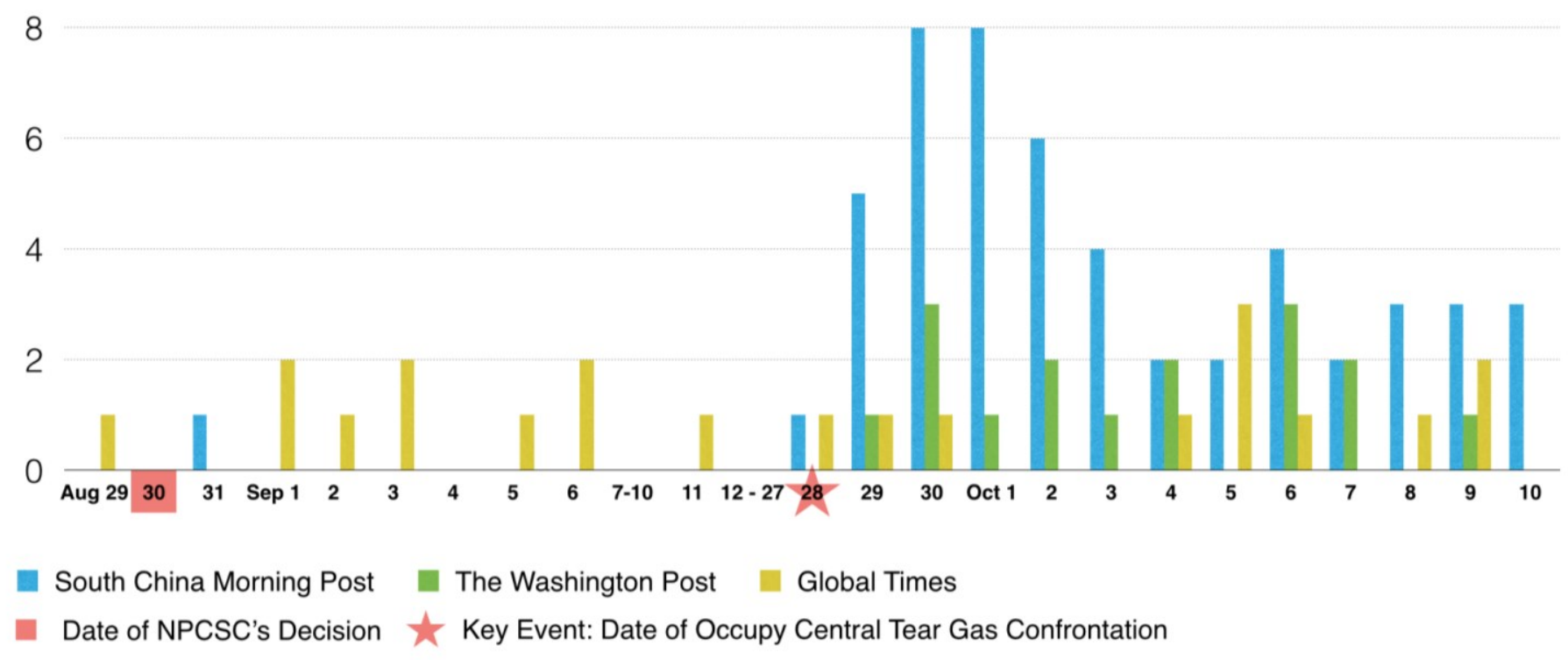

\subsection{Corpus Article Distribution}

As mentioned previously (see Chapter Two), the corpus totalled 89 news articles: 52 articles from SCMP, 16 from WP, and 21 from GT. Figure 2 shows the distribution of articles during the period of August 29, 2014 to October 10, 2014 by newspaper.

Although there was greater news coverage of the Umbrella Movement by SCMP, this did not affect the outcomes of my research - since the amount of news articles a news organization produces within a given time frame also provides insight to how the movement is framed. SCMP followed the movement heavily, with numerous daily reports following the Key Event on September 28, 2014. SCMP included local, detailed, 
hourly updated coverage that generally depicted the protesters positively and helped advance and legitimize the movement. WP's reporting of the Umbrella Movement also emerged after the Key Event, but its coverage was sparser in comparison to SCMP. WP's articles drew larger conclusions and connections from the movement from an international perspective. News coverage from GT was heavier after the announcement of NPCSC's decision on August 30, 2014, in an attempt to prevent the movement from occurring and gaining support from those who were against the decision. After the Key Event, GT did not report heavily on the movement and its news discourse aimed to delegitimize the protesters and their cause, while justifying the actions of the HKSAR and Central government in support of the NPCSC's decision.

\subsection{Micro-Level Frames}

Micro-level frames are specific to a certain issue, which in this case, is the movement itself. These frames can also be tied to more generic frames as well, such as a conflict frame or economic frame. By introducing these frames as issue-specific microlevel frames, we are able to have a better understanding of how this movement is communicated by the three online news platforms studied. The first micro-level frame can also be identified as a causal frame, introducing the primary cause of the movement from the perspective of each news source. While South China Morning Post (SCMP) and Washington Post (WP) identified the Standing Committee of the National's People Congress' (NPCSC) decision to be the primary cause of discontent among protesters, Global Times (GT) claimed that there was only an exclusive group of radicals stirring up trouble. These frames develop and rationalize the purpose of the movement's existence. 
Another micro-level frame building from the causal frames is the Umbrella versus Tear Gas frame. This frame is centered on the issues specific to the events that unfolded during the Key Event on September 28, 2014, where a major conflict between the protesters and authorities emerged. As SCMP and WP portrayed the protesters as the victims to tear gas shot by police, GT's discourse suggested they were the culprits of chaos. The treatment of the protesters and authorities by these news sources provide a foundation for understanding the macro-level frames that unfold in discourses about the Umbrella Movement.

\subsubsection{Causal Frames: NPCSC's Decision as the Catalyst of Protest}

There are two positions presented as the cause of the movement from the examined news discourses. SCMP and WP held one similar stance, while GT had an opposing position. While all three news sources attributed the cause of the protest as a reaction to the NPCSC's decision that was released on August 30, 2014, stories had the tendency to report attitudes from only one side. The first stance conveyed in the news discourses of SCMP and WP placed the Central government at fault, claiming the decision was unfair. The NPCSC's decision was depicted as a form of punishment that "slapped tight restrictions" onto election procedures for the 2017 election of Hong Kong's Chief Executive. The decision was seen as a violation of the Basic Law, as it does not ensure the people of Hong Kong will be able to elect their own Chief Executive through methods of universal suffrage by 2017 . The decision, as discussed in greater detail in Chapter Three, was conveyed in news discourses as a restriction to the electoral process, as citizens of Hong Kong will only able to elect their Chief Executive through 
pre-screened candidates chosen by its "Communist leaders". This was identified as a way for the Central government to "weed out" any candidates that opposed the Communist party. Protesters, also coined as "pro-democracy forces" by the media, were engaging in a "long-term fight" against the Central government for the people of Hong Kong to be able to vote through methods of universal suffrage.

The opposing stance by GT attributed the cause of the protesters to a minority of "extremists" and "radicals" from Hong Kong's pan-democratic camp. As GT produces news from publications released from the Communist Party of China (CPC), their reports on this movement focus on legitimizing the NPCSC's decision. They do so by stating that only a small minority of extremists were unsatisfied with the NPCSC's decision, while the majority of people in Hong Kong felt the decision was a reasonable solution, as it complies with the Basic Law. News coverage from GT also suggested that the protesters were generating an "illusion" that the protests had many supporters, when in reality; there was only a small minority of "troublemakers". GT heavily emphasized that the NPCSC's decision would strengthen and support the "One Country, Two Systems" policy that governs Hong Kong and abides by the Basic Law, as Hongkongers would still be able to vote through methods of universal suffrage, suggesting that no "promise" was broken. GT asserts that public opinion in Hong Kong supports the Central government's decision and it is only the extreme pan-democratic camp that is "manipulating" public discourses that are responsible for the unreasonable protests. Thus, all reports from GT on the 
movement in Hong Kong aimed at delegitimizing protesters and were targeted at dissuading supporters from joining the protests.

\subsubsection{Umbrella versus Tear Gas}

"People use peace and hope, while the government used tear gas and pepper spray."

- Benny Tai (SCMP)

The night of the Key Event was a pivotal moment that defined the Umbrella Movement. At first, this movement was simply identified as the Occupy Central Movement by SCMP. However, after the Key Event, local and international news outlets began referring to the movement as the Umbrella Movement or Umbrella Revolution. After Hong Kong police fired " 87 canisters of tear gas" and pepper spray at protesters who used umbrellas to protect themselves, OCLP's original goals began to shift, and the movement began to carry on a new identity. Protesters who were not initially associated with OCLP were reported to have joined the crowds on the streets. Prior to the Key Event, SCMP's reporting on the movement was aligned with OCLP's initiatives for Hongkongers to achieve universal suffrage by 2017. After the Key Event, however, the movement extended its frames and goals - while advancing the movement as a fight for universal suffrage, the protest was also portrayed as a fight against police injustice and government corruption. The Umbrella versus Tear Gas frame was implemented by all three news sources with different purposes - each generating competing representations of reality through the same Key Event. SCMP used the frame to recruit sympathizers for the protest and legitimize protesters' acts of civil disobedience. WP's coverage supported the protesters as well, while also using this frame to highlight the dangers of the Central 
government. At the same time, GT used this frame to delegitimize the movement and protesters through their acts of violence and disturbance to the city.

News coverage from SCMP on the night of the Key Event depicted protesters as "peaceful", "civil", and "rational". The protesters were practicing acts of civil disobedience by blocking the main streets of Hong Kong, but were not engaging in any violence. Protesters were reported to be doing homework, distributing water, and clearing the streets of garbage, acting as "self-organizing guerrillas". News discourses attested that the event did not become chaotic until authorities were engaged. Thus, asserting that authorities had "no reason" to shoot "87 canisters of tear gas" and pepper spray. Protesters were in organized, peaceful crowds who had no means of protection, other than the umbrellas they were using earlier to shield themselves from the sun earlier in the day. Subsequent reporting of the movement after the Key Event shifted its focus from OCLP members aiming for universal suffrage to other situational events. SCMP reported protesters being harmed by Hong Kong police, Chief Executive Leung's unsatisfactory response to protesters, and violence committed by members of Anti-OCLP, rumoured to be triad members involved in organized crimes hired the Central government of Beijing. Many protesters who were not originally part of OCLP or the student movement were said to have joined due to the awareness of the event brought by tear gas to demonstrate the injustice brought by authorities. This frame extended to the incompetence of Chief Executive Leung's role as a leader, and thus, mobilized supporters to march outside Leung's quarters and demand for his resignation. However, there was still no response from Chief Executive Leung or the Central government. SCMP's coverage highlighted the lack of response from Chief Executive Leung and the Central government to 
demonstrate his absence of concern for Hong Kong and its people. While SCMP's use of the Umbrella versus Tear Gas frame aimed to legitimize the protesters, its news discourse also extended the initial goals that originally defined the movement. Even though protesters were originally mobilized by NPCSC's decision, the Key Event did amplify the importance of achieving universal suffrage in Hong Kong, while also demonstrating the injustice committed by the Central government and HKSAR, calling for the immediate need of collective action.

There were overlapping frames in news discourses produced by WP and SCMP, such as the peaceful nature of protesters and the injustice perpetrated by authorities that released "87 canisters of tear gas" and pepper spray. However, WP's discourses involved more international commentary, such as the inclusion of an editorial by Chris Patten, the former British Governor of Hong Kong. These discourses used the Umbrella versus Tear Gas frame to highlight the danger of the Central government in repeating the Tiananmen Square incident from 1989. WP's discourses suggested that the Umbrella Movement would lead to a repeated history without international supporters preventing China from harming the protesters. Thus, WP utilized the Umbrella versus Tear Gas frame to highlight the violent nature of the Central government and justify the newsworthiness of the Umbrella Movement as an important event to be aware of. Further explanation of the Tiananmen 2.0 frame will be further explored in this chapter.

GT stated that "foreign media outlets" have blamed the police for using "excessive force" on the protesters. In defense, GT discourses used the Umbrella versus Tear Gas frame to divert blame from the police back onto protesters. GT paints a different picture of the events that took place during the Key Event. Instead of police 
firing tear gas and pepper spray onto innocent protesters for "no reason", GT asserts that the protesters were chaotic prior to any confrontation with the police. The reason police released tear gas and pepper spray was due to protesters continuing to charge at police blockades despite their instruction not to. In an attempt to control the crowds, the authorities stated they used the "minimum force necessary" against the protesters. GT's news discourses suggested that unfavourable sentiments towards the police were associated with the social climate of the time, in regards to the US Ferguson protests that occurred earlier in the year. When confronted by police, protesters were mentioned to be "raising their hands non-violently", a gesture that is symbolic to the Ferguson protests. GT discourses aim to make the connection that these unfavourable attitudes with the police stem from the Ferguson protests of unjustified police violence, rather than the outcomes from Central and HKSAR government's actions. GT discourses communicate that the police were doing their job and preventing the spread of chaos initiated by illegal actions that were "undermining social order and stability". News reports by GT continued to attest that the protests were illegal and aimed to delegitimize the movement and protesters.

The Umbrella versus Tear Gas frame that communicates the situational conflict in the Umbrella Movement provides the foundation for the construction of macrolevelled thematic frames. The ways in which each side was portrayed in the Umbrella versus Tear Gas reflects the treatment of protesters and the Central government. These sentiments are extended in the macro-levelled frames as well. While the Umbrella versus Tear Gas frame has been repeated throughout history as the good versus evil, peace versus violence, its simplistic narrative is used to frame the situation of the Umbrella 
Movement. Thus, while SCMP and WP discourses frame the authorities as the reason for violence, GT discourses defend the authorities to be simply controlling the chaos initiated by illegal protesters.

\subsection{Macro-level Frames}

Macro-level frames are much more broad than micro-level frames and are connected to the surrounding culture. The ways in which the micro-level frames were constructed can be partially explained by cultural differences, which are exemplified in the macro-level frames. Examining these frames cross-nationally can allow us to study how these macro-level frames were constructed, giving the opportunity to compare and contrast. These frames were categorized as the Democracy as Remedy, Tiananmen 2.0, and Protesters as Manipulation frames that emerged most prominently from news discourses on the Umbrella Movement from SCMP, WP, and GT. The ways in which these frames were produced is partially influenced by the surrounding culture of the news organizations. Thus, these macro-level frames can also lead to greater insights on the surrounding cultural attitudes towards the Umbrella Movement.

\subsubsection{SCMP: Democracy as Remedy}

While the original goal of the Umbrella Movement was aligned with OCLP and student groups' goals to achieve universal suffrage in Hong Kong by 2017, messages produced in SCMP discourses began to shift away from simply achieving a political goal to making the protests relatable to all Hongkongers. Democracy as Remedy is a macroframe that situates the news discourses produced by SCMP into Hong Kong's larger 
cultural context. This frame illustrates how SCMP's discourses communicate that the movement's fight for democracy is important because it will cure all of Hong Kong's current societal problems, such as the wealth gap and preservation of Hong Kong identity. SCMP supports the idea that Hongkongers are "ready for democracy" and attempts to detach more ancient connotations of Hongkongers as politically apathetic citizens. This frame is further supported through discourses that suggest Hong Kong's current form of governance is no different than colonialism, with their freedoms consistently becoming more limited. Lastly, the NPCSC's decision is seen as a form of assimilation by the Central government, whereby protesters need to take a stand and preserve Hong Kong identity through means of universal suffrage.

Historically, Hongkongers were defined by their lack of interest in collective political concerns and were more concerned with private, economic matters. However, as mentioned in Chapter Three, after the July 1, 2003 large-scale protest against the antisubversion law, Hongkongers' attitudes towards political issues began to change. Due to the success of the event, Hongkongers began to see the power of collective action in generating minor hiccups on the economy and garnering a favourable response from the HKSAR. Chan and Lee (2007) argue that this event has transformed the ways in which Hongkongers lead the pro-democracy movement. Coined as the "July $1^{\text {st }}$ effect", the event in 2003 also transformed media discourses on the pro-democracy protest to become more positive, despite the political orientation of the news outlet. Prior to the July $1^{\text {st }}$ protests, conservative newspapers had the tendency to "economize" street protests, suggesting that participants were only protesting due to economic concerns (Chan and Lee, 2007). Once economic conditions improved, conservative discourses suggested that 
protests would also stop and the will for political change would vanish. However, after the July $1^{\text {st }}$ protests, even conservative news sources covered pro-democracy protests in Hong Kong positively, as it matched the sentiments of public opinion in Hong Kong. Since SCMP leans towards the left in terms of political orientation, their discourses are more supportive of the pan-democratic camp in Hong Kong. Thus, their news content produces more mobilizing discourses that support and legitimate the movement.

SCMP's coverage aimed to steer readers away from the notion that Hongkongers were mostly concerned with economic prosperity. Their coverage avoided citing reports on any negative economic impact the movement may have caused. Instead, SCMP's coverage suggests that the protests had little effect on Hong Kong's economy. While not all Hongkongers are seen as politically apathetic, there still remains a "silent majority" in Hong Kong who are unmoved by the protests, do not voice their political views, or choose not to have any. SCMP uses guilt-driven rhetoric to mobilize this silent majority, urging individuals who are not on the streets protesting to reflect on themselves and what it means for the future generation. Even as local businesses are disrupted, SCMP provides anecdotes from shop owners who communicate being unbothered by the disturbance to their business and join in the protests themselves. Quotes featuring bystanders who complain about the inconvenience of the protests and their disturbance to Hong Kong's economy are portrayed as arrogant and insensitive individuals who garner no sympathy. While preserving Hong Kong's status as a key financial hub in China is important, SCMP's news discourses suggest that when it comes to fighting for democracy, economic prosperity can be temporarily pushed to the side. 
The NPCSC's decision is communicated as "fake" democracy and not a reflection of "genuine" universal suffrage. For universal suffrage to be considered "genuine", Hongkongers would be enabled to elect their own candidates for Chief Executive in popular election. NPCSC's decision fails to allow this and disregards the election process for Chief Executive as part of the process of universal suffrage in the Basic Law, giving its name in SCMP's coverage as "Chinese democracy". While China promised to advance democratization in Hong Kong after the Handover in 1997, the NPCSC's decision is seen as a violation of that promise. Thus, Hongkongers perceive the current system as another form of colonialism. While no longer under British rule, SCMP discourses assert that Hong Kong is no better under its present day rule by local tycoons and the Communist Party of China (CPC) at a distance. Previously elaborated in Chapter Three, mainland China is seen as the leading influence of Hong Kong's social problems. Hong Kong's security and well-being lies in its ability to distance itself from mainland China - and to do so, they must achieve true democracy. Trapped in a regime no different than its days as a crown colony, news discourses from SCMP suggest that pushing for democracy is seen as the only escape.

Democracy in Hong Kong means more than a normative ideal form of governance to achieve. The promise for democracy is engrained as part of the identity of Hongkongers. Since the Handover, Hongkongers have been residing in a "peripatetic zone", as they live in the middle of two cultural divides from British colonial rule to current-day China (Flanagan, 2014). Hong Kong's “core values" are defined by the Rule of Law, having greater freedoms, and the rejection of Communism (Garrett and Ho, 2014). Underlying discourses suggest that obtaining democracy is imperative for the 
retention of Hong Kong identity. Without the fight for democracy, Hong Kong will become "just another Chinese city". SCMP provides anecdotal evidence that reveals local Hongkongers' sentiments towards "assimilating" with mainland China. Discourses suggest that even if the movement is unsuccessful in changing NPCSC's decision in the short-term, the movement has still succeeded in communicating that Hong Kong is ultimately different from mainland. NPCSC's decision is expressed by news discourses as another way for China to consume Hong Kong and their identity to be part of China's whole. The identity of a Hongkonger is outside of being Chinese, as protesters chant: "We're not Chinese. We're Hongkongers!" Instead of being "trained" to be Chinese, Hongkongers have rejected mainland identity and through this process, have created their own defined by these sentiments. A part of being a Hongkonger has become the rejection of mainland identity.

\subsubsection{WP: Tiananmen 2.0}

News discourses by WP surrounding the Umbrella Movement defined a clear common enemy: the Communist Party of China (CPC). Referencing China's history, the Tiananmen 2.0 frame is described to be foreshadowing the potential violent outcome of the Umbrella Movement. The 1989 Tiananmen Square student-led movement resulted in the massacre of thousands of students who did not refuse to move when confronted by authorities. Reflecting on the Key Event, WP discourses see the Umbrella Movement to be mirroring the student protests from Tiananmen. According to WP, there is an international consensus that attests that the $\mathrm{CPC}$ is likely to "forcibly crush" the protest movement if it persists. News discourses from WP suggest that the violent use of tear gas 
and pepper spray over peaceful protesters during the Key Event indicate the CPC may commit violent acts, repeating history from the Tiananmen Square incident.

WP communicates the importance of spreading awareness of the movement - not necessarily reinforcing its goals to achieve universal suffrage - but mainly to ensure the "eyes of the entire world" are watching China. Due to freedom of the press in Hong Kong and the ability to access to all social media platforms, WP's discourses suggest that China can no longer conceal their actions, as they have attempted to do so during the 1989 Tiananmen Square student protests. This is communicated by WP discourses as the only form of protection that is preventing authorities from controlling the protests in more violent ways. Even though China has been censoring the movement in its own regional outlets, WP suggests that China cannot erase parts of its history to the rest of the world (as it attempts to do so with its Great Firewall over the internet and immense censorship in the press). Their rhetoric questions why China is censoring news about these protests in Hong Kong if they have nothing to hide. China's control over censorship in the media and its lack of transparency in the government is associated with a lack of trust and accountability; depicted in WP as features of an "authoritarian regime". The underlying discourses published by WP suggest that government censorship is a feature of China's communist regime exclusively, while democratic societies foster greater transparency and accountability between the government and its citizens.

Historically, Britain and the United States had vested interests in tracking Hong Kong's pro-democracy political movements, often criticizing China for its human rights violations (Garrett and Ho, 2014). Garrett and Ho (2014) have noted that Britain and the United States have regularly published reports on the protests in the HKSAR region, 
while also documenting the Central government's responses to them. Documenting Hong Kong's protest culture is seen as a way to detect the health of the "One Country, Two Systems" ideology (Garrett and Ho, 2014). Chris Patten, Hong Kong's last British Governor, was featured in an editorial published by WP. In response to the NPCSC's decision, Patten states:

No one told the people of Hong Kong when they were assured of universal suffrage that it would not mean being able to choose whom they could vote. No one said Iran was the democratic model that China's Communist bureaucracy had in mind, with the Chinese government authorized to exercise an effective veto over candidates.

Patten furthers the notion that the NPCSC's decision does not foster "real democracy", but rather a "fake" version that was also adopted by Iran. The mention of Iran is, perhaps, a subtle indication to justify Britain and the United States' joint invasion in Iran in 1953 to overthrow the Prime Minister at the time that was seeking to nationalize Iran's oil assets. The United States has been known to use democracy as the crutch of their rationale for international intervention, in cases such as Afghanistan and Iraq. As the global "freedom fighters" of the world, WP discourses are aligned with the United States' concerns to comment on any supportive change to escape from authoritarian regimes and fight for democracy.

\subsubsection{GT: Protesters as Manipulation}

All news discourses produced by GT were focused on framing protesters as motivated by an extremist minority, and therefore should be suppressed. The protesters are coined as members from the radical opposition camp that has been holding Hong Kong "hostage for a long time". The underlying assumption from this frame suggests that 
actions from the minority are not reflexive of sentiments from the majority. Thus, voices from the minority are perceived to be illegitimate because they do not garner "popular support". GT asserts that these extremists are simply "manipulating" public discourses in Hong Kong to their favour, generating an "illusion" of support for the movement. These radicals are said to have "eroded the tradition of rationality and the rule of law, permeating radicalism and populism into Hong Kong's ideology”. These discourses reveal how the Central government may feel threatened by the protests, as all GT news reports on these topics aimed to stifle and delegitimize the movement. By asserting that the protesters are engaging in illegal activities, disobeying their country's leaders, and generating instability in society, this frame indicates the government's fear of groups who challenge the status quo. In an attempt to maintain the status quo, GT's discourses attempt to silence the voices of the minority and spin any real influence pro-democracy activists have made on society as a form of manipulation.

Aside from producing direct reports illustrating the protest movement in GT's own perspective that supports the Central government's decisions, GT has also supported conspiracy theories surrounding the movement. While GT news reports claim that China has "no ulterior motives to destroy Hong Kong", the West is blamed as the "outside forces" that are manipulating the students ("youngsters") with their "tricks":

Hong Kong is a small society, but it is not isolated from the big picture of the Asia-Pacific game. Hong Kong has no capital to make mistakes in political issues, and making a fuss over Hong Kong's rule of law is a trick played by the West to ruin the region. Hong Kong must know it is a financial center and tourist destination. These are the real things that deserve to be safeguarded.

This statement accuses the West as the perpetrator of the movement, with its end goal to see China and Hong Kong suffer rather than succeed. Although there is no proof that 
would indicate this theory is true, news stories in GT continue to assert these claims as fact. Instead of students and members of the pro-democracy movement protesting against the Central government's decision, supporting this conspiracy theory deflects blame from the Central government to external influences from the West. This discourse also squanders and delegitimizes the fight for democracy as a trick and simply a move in an international "game", rather than a legitimate movement with a large group of supporters. This theory treats the advancement towards democracy as a tool that is used by the West as a form of manipulation. Also, by suggesting the movement is orchestrated by the West, GT discourses push for more attention onto tangibly observable aspects of society - asking Hongkongers to focus on maintaining the city's success as a key financial centre instead and focusing on tourism. This conspiracy theory further supports the frame that illustrates how discourses in GT have suppressed voices from the minority that aim to challenge the status quo to achieve political change.

\subsection{Discussion on Cross-National Frames}

Even though the Key Event was a phenomenon that happened in a specific place and time, there were three different perspectives just from this one event during the movement. Pan and Kosicki's (1993) statement may explain why this is the case: "The domain in which news discourse operates consists of shared beliefs about a society" (p. 57). These shared beliefs are adopted and "accepted by a majority of society as common sense or conventional wisdom..." which creates "the parameters of a broad framework within which news discourse is constructed, transmitted, and developed" (p. 57). Kwon and Moon (2009) call these shared beliefs "enduring values" (p. 271), which they claim 
are often unintentionally embedded into news discourses. In this thesis, the term "enduring values" is used in reference to the perceived values that reflect the perception news media has about the shared beliefs that are accepted by the majority of individuals within society. In this case, coverage from SCMP would appeal to the "enduring values" that are commonly held attitudes or beliefs within Hong Kong society. For example, news reports from SCMP were aligned with groups that support Hong Kong's prodemocracy movement and appealed to Hongkongers who reject mainland identity. These enduring values can be left undetected in its host society, as they have become engrained within individuals of a society (Kwon and Moon, 2009). Thus, when identifying frames in a cross-national perspective, these enduring values become more apparent and obvious when contrasted against each other.

The findings have revealed that although news from GT and SCMP were produced from the same country, their coverage of the Umbrella Movement contained opposing perspectives. Media frames from WP were more closely aligned with SCMP, although they were generated for different purposes. SCMP and WP discourses reveal that both societies share similar enduring values that associate freedom with democracy. It may be obvious that WP is supportive of the protests because the movement is representative of the fundamental rights and beliefs the people of the United States hold in regards to a democratic society. As a country ruled by only one political party, China is perceived as a dictatorship in discourses from WP, suggesting this system of ruling is wrong and represses its own people. For this reason, SCMP and WP avoided references to the Basic Law and issues on legality because their discourses were grounded in moral and ethical appeals. Instead of focusing on what is currently deemed as "just", frames 
from SCMP and WP supported protesters challenging the status quo to fight for what should be just. This is why frames from SCMP and WP focused on the CPC as the common enemy, because its system of governance is seen as an inferior and morally unjustified way of rule in comparison to more democratic models of governance.

WP editors have adopted the Umbrella Movement as part of their own news by engaging in a mode of collectivistic storytelling (Nossek, 2004). As mentioned in Chapter Two, collectivistic storytelling occurs when international news is perceived as "our" news versus "theirs". A key characteristic of collectivistic storytelling is that news stories produced tend to be less objective and carry more cultural narratives (Nossek, 2004). This theory is supported through my findings, as coverage from WP was heavily framed in favour of the protesters. Although editorials are not meant to be objective, the editors of WP made it clear that their stance was to support the Umbrella Movement, as all their more professional news stories only provided one side of the story that framed the protesters as peaceful freedom fighters. This is embedded in not only cultural narratives from the United States, but also related to the chain of pro-democracy movements that its government has voluntarily engaged itself in, exemplified in the War on Terror to the Arab Spring movements that emerged late in 2010. By including news discourses that support the Umbrella Movement, WP is helping reinforce previous decisions and actions made by the United States on a global scale. Although WP and SCMP are from news organizations that grant greater journalistic freedoms, the news they produce still carry embedded cultural frames, which in this case, are supportive of the advancement of prodemocracy movements. 
While Kwon and Moon's (2009) concept of enduring values can be applied to news discourses in SCMP and WP, the same concept may not pertain to GT. This is because news discourses from GT do not necessarily reflect the beliefs shared by the majority of society, as journalists are more heavily censored on what they are allowed to report and the content of their reports. GT's coverage had very few mentions of the Umbrella Movement as a protest movement until international news outlets began producing heavier coverage. News reports from GT became very reactive, providing an opposing perspective to defend the position of the Central government. Its news discourses suggest that the enduring values communicated in frames produced by GT point to stability and unity, aligned with values held by the CPC (Brown, 2012). GT's frames aimed to delegitimize the movement and focused on using rational appeals, grounded by the Rule of Law, which determined the illegality of the event and thus, focused on the conflict and chaos inflicted by protesters. Since GT is a news outlet controlled by the CPC, journalists cannot produce a wide-variety of societal viewpoints and must report what the $\mathrm{CPC}$ approves of, altering their freedom of communicating other representations of reality. Due to this heightened form of censorship, it is not possible to determine if discourses in GT are representative of enduring values of all of mainland China. It can be determined that news discourses constructed by GT were more concerned with maintaining a positive image of the $\mathrm{CPC}$ rather than true intentions of protesters engaged in the Umbrella Movement. 


\subsection{Framing Processes and Social Movements}

A great deal of this research focuses on how mainstream media can use framing processes to legitimize and delegitimize social movements. McAdam, McCarthy, and Zald (1996) identified the importance of framing processes for social movements to deliver the significance of their cause to audiences that may have similar values to either support or join their cause as well. Supportive coverage of the movement can involve processes of frame alignment, described as the connection between an individual and social movement organization's “interpretive orientations", such as values, interests, beliefs, and goals (Snow et al., 1986). While framing processes are seen as separate from mobilizing structures, framing processes can help facilitate the mobilization process of social movements. Media not only produce social knowledge, they can also report on calls to action by protest leaders and act as a legitimate source for protest information. SCMP's media coverage acted as a facilitator for mobilizing supporters, as their daily coverage provided hourly updates and announcements of the protesters' locations and their plans for action. That is not to say that the coverage from SCMP was able to shift attitudes on the movement, but it does allow individuals to act upon their existing attitudes by knowing the time and place of the protests. Chan and Lee's (2007) research on large-scale protest movements in Hong Kong have also attested that newspapers were seen as the most importance source for achieving "action-facilitating information" that provides information to encourage mobilization.

SCMP's coverage provided collective action frames that identified what the problem was through diagnostic frames, and how the problem can be solved through prognostic frames (Gamson, 1992). Social movement organizations "present and package 
their issues and concerns to highlight the injustice involved, construct the collective identities and interests of the people affected, create alliances with other groups and pinpoint the possibilities for change" (Chan and Lee, 2007, p. 6). Although this research does not compare and contrast the areas of overlapping messages produced by OCLP and mainstream media, a distinction could be made among the messages from the media that were congruent with the social movement's intended goals. SCMP was able to package the issues and concerns of members of the Umbrella Movement by providing thorough day by day, hourly coverage of the movement that was in favour of the protesters' preferred representation. Diagnostic frames have depicted the NPCSC's decision as the key cause of protesters' immediate aggressions, which was also aligned with the movement's intentions. The construction of effective prognostic frames are equally, if not more important for the success of social movements, as they call for the action of people. For individuals to engage in the movement, they must believe that the issue concerns them and that their participation can solve the issue at hand. This is where I believe frame alignment processes become more important, as they are able to apply concerns from the social movement into a more diverse pool of concerns, attracting more supporters to the movement.

News coverage from SCMP and WP have engaged in frame alignment processes, while news from GT have not. Snow et al. (1986) have classified four modes of frame alignment: frame bridging, frame amplification, frame extension, and frame transformation. These four processes have been discussed in greater detail in Chapter Two. Coverage from SCMP mostly engaged in frame amplification, by consistently sharing the movement's issues and events in its news coverage. Frame amplification 
encompasses both value and belief amplification. SCMP has amplified the values of the movement, exemplified through the Democracy as Remedy frame that communicates the importance of achieving democracy to improve Hong Kong society. The Democracy as Remedy frame suggests that achieving democracy is not just a goal that is motivated by the pan-democratic camp in Hong Kong, but rather a movement every Hong Kong citizen should support and is already supporting. The goal was to break down the movement as a case for universal rights. This allowed citizens with no political affiliation in Hong Kong to also participate, inspiring greater means to collective action. SCMP was also able engage in belief amplification, strengthening the efficacy of action and ability to identify the possibility of change through the movement. The belief that people power would affect the protest outcomes definitely weakened throughout the course of the protests, as the Central government would not budge to protesters' demands. However, news coverage from SCMP continued to assert that the movement was a success in terms of generating a "social awakening" in Hong Kong society, communicating the importance of the pro-democracy movement. Although the Umbrella Movement may not have achieved its short-term goals for NPCSC to retract its decision, SCMP discourses continued to reiterate the belief that change will not occur automatically in the future without the collective support from Hongkongers.

The most prominent frame alignment process WP adopted was frame extension, a practice that enables more potential supporters of the movement to grow. While WP discourses engaged in similar modes of frame amplification as SCMP, the original framework that was constructed as a fight for universal suffrage was extended to a greater issue, exemplified in the Tiananmen 2.0 frame. The Tiananmen 2.0 frame extended the 
initial frame about achieving democracy to the fear of China committing violent acts against protesters. This frame not only strengthens the initial framework that strives for democracy by legitimizing the cause of the movement, it also extends the frame to an idea anyone can support, enlarging the group of potential advocates and supporters for the movement. In order to support the Umbrella Movement, audiences do not necessarily need to possess knowledge of Hong Kong's political history, but rather see China as the common enemy who may condemn the protests with force, as the government has previously in 1989. This is an issue that the any audience can support, giving a more controversial topic a simpler narrative to accept and align with.

Instead of citing the protests as a movement supported by the majority of Hongkongers, as depicted in discourses by SCMP and WP, coverage from GT asserts the protests are only part of Hong Kong's extremist pan-democratic camp. GT's reports distorted the intended message from social movement's organizers. It can be argued that GT news articles did not engage in any modes of frame alignment. They have transformed the original framework of the movement to serve its own purposes. The Protesters as Manipulation frame illustrated the ways in which GT blames protesters to be manipulating the public, and also asserts the protesters themselves are manipulated by external forces. Constructing and supporting conspiracy theories that suggest the West have been behind the protests are an attempt by GT to reconstruct the events to delegitimize and stifle the movement. The only reason GT has reported on the movement 
was not to amplify or extend the movement's original goals, but rather to defend the position of the Central government.

\subsection{Conclusion}

The goal of this chapter was to identify frames within the Umbrella Movement and how these frames played a role in generating representations of reality. Studying the frames cross-nationally revealed how one event can be portrayed differently across three online editions of established newspapers. Micro-level causal frames were first introduced to describe the key cause of the protests by each newspaper. The Umbrella versus Tear Gas frame further illustrated the different ways in which the movement was initially covered after the Key Event. The ways in which the Key Event was reported set the tone for how the movement is framed on a macro-level for each news source. For SCMP, the Democracy as Remedy frame emerged to amplify the movement's cause as a fight for democracy, while also aiming to generate greater collective action in Hong Kong. Discourses from WP used the Tiananmen 2.0 frame to extend the message that democracy is a necessity to achieve in order to escape from authoritarian regimes, which have a true potential to be dangerous. Lastly, GT reports led to the Protesters as Manipulation frame that aims to uphold the image of the $\mathrm{CPC}$ while delegitimizing the protesters who challenge the status quo. The differences in cross-national coverage stem from national enduring values, which are commonly held, shared beliefs in society. These differences apply for SCMP and WP, as their stories were produced with greater journalistic freedoms and have a culture of generating news stories that tend to appease its audiences. However, the same concept of enduring values cannot be applied to 
coverage from GT, as it is impossible to detect whether its news stories reflect the "enduring values" of a society, since it is a heavily censored news source. Instead, these news stories reflect the sentiments of the CPC and the values they uphold in order to maintain stability and unity within its system of governance. While it may be possible to learn about general societal attitudes in news discourses produced by SCMP and WP, it is more difficult to detect societal attitudes from the coverage of GT. Insights from the next chapter on corresponding audience comments will hope to bridge this gap and discuss how audiences respond to the existing frames provided in this chapter. 


\section{Chapter: Commenting on the Umbrella Movement}

This chapter demonstrates and discusses the findings from audience responses to the key frames revealed in the previous chapter. Responses to the Democracy as Remedy frame in South China Morning Post (SCMP) gained more critical comments than agreeable, supportive ones. The Tiananmen 2.0 frame produced by WP discourses was predominantly supported within the comments, while GT's Protester as Manipulation frame led to both agreeing and disagreeing comments. As a by-product of studying audience comments accordingly to news frames, there was also an abundance of critical commentary on the quality of journalism. All three news sources experienced critique of its coverage being biased or propagandistic. In doing so, audiences themselves were compelled to remedy any "inaccuracies" within the news articles by sharing alternative sources and personal anecdotes. By acknowledging the treatment of information in news articles, commenters attempt to fill the gaps from news discourses by providing additional knowledge accumulated from their own subjective realities.

\subsection{Audience Responses to Media Frames}

There was a great variety of responses gathered over six thousand comments. This chapter provides the key findings that correlate with discourses produced from the key news frames discussed in the previous chapter. The findings revealed that comments were not always aligned with the media's perspective, allowing many alternative voices and viewpoints to emerge. This section provides the most prominent and apparent aggregation of discourses in response to the mainstream news discourses from South 
China Morning Post (SCMP), the Washington Post (WP), and Global Times (GT) on the Umbrella Movement.

\subsubsection{Comments from SCMP}

The key theme that was drawn out from the Democracy as Remedy frame described the movement's fight for democracy as a solution to remedy contemporary issues in Hong Kong society. SCMP accomplished this by minimizing any coverage that would suggest the movement had any negative impact on Hong Kong's economy and only providing anecdotes from business-owners who were not concerned with their bottom-lines. SCMP discourses also continuously referenced the NPCSC's decision as "fake" democracy that would simply perpetuate colonial rule over Hong Kong. Lastly, the struggle against mainland forces was portrayed as a critical move in order to protect their cultural identity as Hongkongers.

Democracy is approached with a great deal of scepticism by commenters. Some comments suggest that democracy is simply a "façade", is "too idealist", is a "Western political model", does not generate unity, and is based on "popularity over performance".

Debates on the normative quality of democracy for Hong Kong in contrast to other countries were used for commenters to either justify why Hong Kong should or should not strive for democracy as their mode of governance. User "notjuststones" attests that: "Democracy is not democracy any longer. It really never was anyway, it's just an induced state of mind that people want you to believe". Along the same line of inquiry, user "yunxx" states: "The meanings of terms like 'facts', 'universal suffrage' and 'democracy' are socially constructed and defined by elites". Others attribute democracy as only a 
Western model that would not work in China due to its population. While the normative model of democracy suggests it is the best way for people to rule themselves, user "brutus216" states, "not everyone is fully informed. Not everyone is capable of making intelligent decisions". Commenters continue to share why they believe democracy is not the best mode of governance, pointing to the United States as an example of democracy "gone wrong", with a high wealth gap in society and the illusion of party politics as representative of the majority. Users rationalize their arguments with references to news articles, books, philosophers, and history as evidence. These commenters assert that democracy is not the solution to all problems in Hong Kong, rejecting ideas from the Democracy as Remedy frame put forth by SCMP.

As SCMP aimed to disassociate its reports of the movement from economic concerns, audiences continued to question the "democratic" goals of the movement. Both supporters and non-supporters of the movement expressed their concerns with the movement being about more than just democracy. Critical commenters asserted that the protesters were "hijacking" democracy as an "excuse" motivated by other demands. Many commenters accept that the NPCSC's decision is not necessarily bad. They claim that the decision follows the Basic Law and assume that the Central government would not choose a leader that would harm the HKSAR. Instead, many commenters theorize that it is a combination of socio-economic factors that has generated discontent that initiated the movement. For example, the user "minutia40" states:

If you want to understand what's going on in Hong Kong, you can't focus solely on the beauty of democracy and the adorableness of the students. The democracy movement is also embedded in a matrix of money, subterfuge, 
compromise, subordination, propaganda, and manipulation. In other words, it's good old-fashioned politics, Hong Kong and Beijing-style.

The source of these key issues is associated with the push-and-pull between Hong Kong and Beijing. Mainland China is pinpointed as the "target" creator of these issues, as they are perceived to be the culprits for making property prices soar and raising the cost of living in Hong Kong as a whole. Commenters have expressed their concerns with the vulnerability of the middle-class in Hong Kong, creating great uncertainty:

The middle class is disappearing and property and finance oligarchies run the city with Beijing's blessing (provided they let mainland money continue to drive prices up). (“Arn_Thor”).

While SCMP uses Democracy as Remedy frame to shape rhetoric communicating that achieving democracy is a way to preserve Hong Kong identity, comments suggest that Hongkongers are already certain of their own identity. Debates confirmed that Hong Kong identity is not a part of "being Chinese". Some commenters have expressed that they are not proud to be Chinese or do not identify as being Chinese. Therefore, it is not democracy that needs to be achieved in order to preserve their identity. The sentiments of commenters who wish to disassociate Hong Kong from China attest that the movement is not about democracy; it is about "not wanting to be part of China". This willingness for Hongkongers to disassociate themselves from China is tied to issues of displacement they sense within their own city by mainlanders and mainland influences. These comments 
have reinforced the reasons why Hongkongers have rejected mainland identity, addressed earlier in Chapter Three.

\subsubsection{Comments from Washington Post}

Expecting the past to affect the present, the Tiananmen 2.0 frame generated from news discourses in WP attest that the Umbrella Movement may end in the same violent manner as the student-led protests of 1989 at Tiananmen Square. This discourse suggests that the world should be aware of the movement to hold China accountable for its actions. With the entire world's "eyes on China", they will be unable to erase this history, as it has attempted to previously in the case of the Tiananmen Square protests. Referencing China's inglorious past allows WP to address the Central government's vast censorship issues and showcase the necessity to have democratic systems of government over "totalitarian" regimes, pointing to the $\mathrm{CPC}$.

Within the comment section of news articles in WP, a great number of commenters appeared to genuinely believe the Umbrella Movement was a "replica of Tiananmen". Commenting that the Central government was going to "send in the tanks", users assumed that the People's Liberation Army of the Central government was going to make an appearance at the protest sites. There was a true heightened concern that Chinese tanks and troops were going to "crush the rebellion". Some commenters suggested that sharing support for the movement on social media was important to ensure "the world is 
watching closely" or else "there would be strong arm bloodshed", a similar discourse found within the news discourses of WP.

Concerned with the state of protests in Hong Kong, commenters called upon why the leaders of the United States or the United Kingdom were not intervening to prevent the situation from escalating.

Why isn't Obama giving one of his eloquent speeches (on behalf of Hong Kong) promoting world wide democracy" After all, Obama was publicly for the "Arab Spring" and spreading democracy, even going so-far as calling for the ouster of Assad. Including covert aid to the Syrian "freedom fighters". Based on that history, Obama should be publicly encouraging the "freedom fighters" in Hong Kong and chastising the Chinese leadership for their pending repressive behavior. ("SteveR1")

This generated a lot of heated debates over the United States aiding in the process of democratization in other countries. There was an overall consensus that intervention from the United States in the Middle East and Ukraine were failures. Commenters have also debated the nature of freedom in Hong Kong, arguing that Hong Kong is not in the same state of repression as the other countries that were victims of totalitarian regimes. While one side of commenters attest that it is the United States' duty to take action and protect citizens in authoritarian regimes, others debate that international intervention can do greater harm than good. Overall, many comments from WP were aligned with the Tiananmen 2.0 frame, as there was concern that protesters were in grave danger by the Central government.

\subsubsection{Comments from Global Times}

Asserting that the movement is formed by a group of extremists influenced by the West, GT's discourses produced the Protesters as Manipulation frame that aimed to 
delegitimize groups challenging the status quo and the CPC's political status. Discourses in GT suggested that the protests do not stem from the goal with democracy in mind, but was rather an orchestrated ploy by international forces in the West. In doing so, the Central government takes no responsibility for the NPCSC's decision as a factor that has angered protesters, suggesting they are simply manipulated by Western influences.

There was an equal amount of push back with dissenting comments as there were agreeable responses. For those pushing back, many users seemed to use the comment section of GT to portray another side of the story - the side of the protesters. Since GT discourses did not align with any frames from OCLP or Scholarism, comments were valuable in providing another side of the story. There were commenters who directly copied and pasted messages from Scholarism and OCLP's website and press materials into the comment sections to share their true intentions behind the protests. Messages centered on the NPCSC's decision were deemed incompliant to "international standards" of universal suffrage and would lead to Hong Kong's demise if subjected under the entire rule of the CPC. There were a number of commenters who disagreed with GT discourses, expressing their opinions that Hong Kong should be able to elect its own Chief Executive without being pre-screened by the Central government. While GT discourses asserted that the NPCSC's decision was fair and in accordance to the Basic Law, many commenters disagreed and believed it was a way of limiting Hong Kong's freedoms.

While there were a number of commenters who pushed back against GT discourses, there were a greater number of commenters who supported the frames from 
GT. There was a sense of paranoia and concern that the movement was a mission from the United States' hidden agenda for the West to divide the East:

All those who are loyal to the nation, firmly support the NPC's just and fair ruling. All the western governments, western media outlets, and activist groups who try to meddle in China's Sovereign Internal Affairs - all carry a biased anti-China agenda. They try to find every opportunity and angle to attack China, to divide China, to keep China weak. ("Supreme_Soviet", GT).

The conspiracy theories reported in GT discourses were supported in the comment section. Commenters expressed concerns with "US-installed democracies" that the West uses to "weaken its adversaries". The reality of the conspiracy theory was actualized with more contemporary examples pulled from the United States' interactions with Iraq, Syria, Yemen, Libya, and Ukraine. Instead of attempting to help democratize these countries, commenters were convinced that intervention from the United States has led to greater destruction in these regions. Since China's success is portrayed as the "envy" of the West for commenters, the United States has a reason to disrupt its power by generating controversies in China.

While not all commenters agreed with the active conspiracy theory that the United States was behind the student protests, there was a consistent debate over Western versus Eastern ideologies. The Umbrella Movement is seen as a product of Western ideologies infiltrating Hong Kong society at large. Although there may not have been CIA agents that were directly involved in the movement, these commenters suggest that there is a greater soft power that has influenced the students and protesters. Commenters agreed with GT discourses that highlighted students as those most vulnerable to be manipulated by the West. "Western democracy" is identified by "lies", "disinformation", and "propaganda". Western democracy is merely an "illusion" of equality, while China has 
led to greater economic growth in Hong Kong since the Handover. Commenters have argued over the normative values of democracy, similar to the commenters in SCMP's comment section. To some, Western democracy is seen as merely "motions of electioneering" while China is seen as "objectively" more democratic than the West because it is fulfilling the "People's Will". However, that is not to say all commenters agree with these ideas. A smaller number of commenters have pointed out that GT's articles have failed to grasp the "elementary rules" of democratic societies, such as having the freedom to protest (GT has incessantly deemed the protest as illegal and therefore, unjust). Due to the heightened number of support for GT's news discourses, a number of commenters state that comments that are pro-CPC or anti-Occupy are inauthentic. This Guest commenter claims that paid users from the Central government may have infiltrated the comment section in GT:

Hong Kongers, I know some of you are online right now reading what is on international media. I just want to let you know that we are behind you. We support your rights for a fair and free election. We respect your courage. Don't let these mainland Chinese 50 cent trolls tell you otherwise.

These "50 cent trolls", also known as "wumao", is part of a widely circulated rumour, whereby the Chinese government is claimed to have paid users 50 cents for posting propaganda online. The mention of "paid wumaos" and "50 cent trolls" were apparent across all the comment sections studied. Although my research took into account of repetitive spam comments, I cannot discount all anti-Occupy or pro-CPC discourses as being constructed by "wumaos". While it is possible that some of these discourses may 
be by "wumaos", I have evaluated the majority of non-repetitive anti-Occupy discourses as genuine.

\subsection{Metadiscursive Analysis of User Comments}

As a byproduct of studying audience responses to the news articles, I was able to study not only user attitudes towards the movement, but also the relationship between audiences and news content. Through the act of commenting, users were able to take additional roles in fact checking and detecting bias within articles. This led to a greater discussion on what qualifies as "quality" journalism. At the same time, commenting allowed users to input their thoughts on certain issues to a greater audience, allowing them to make sense of the movement for themselves. This in turn, allowed them to validate their subjective reality with the seemingly objective world, reinforcing and contesting their interpretations of reality with the news articles and other commenters.

The frames identified in Chapter Four have demonstrated SCMP and WP positively framing the movement in favour of the protesters, while GT aimed to stifle and delegitimize the movement. Due to the absolute positive portrayal of protesters in SCMP, a vast number of comments described SCMP's coverage as "biased", "propagandistic", "exaggerated", and "hijacked" by members of OCLP. Commenters questioned the "peaceful" nature of the protests, claiming that the only people who coined the protests as peaceful were members and supporters of the pro-democracy camp. Claims of protesters generating chaos by pushing against barriers, "shouting insults", and using umbrellas to "stab" police officers were listed by commenters to portray a different side of the events. These claims by users were validated by their personal eyewitness accounts. To truly see 
"the full picture", commenters encourage readers to go "into the streets". Commenters assert that "quality" journalism should remain impartial. At the same time, commenters also assume that many of the other commenters were not well informed on the event, asking readers to seek alternative media sources for more perspectives. In order to understand the movement and events that have unfolded, commenters ask readers to experience the movement for themselves, while others provide alternative sources.

There is a double-edged sword for protesters seeking positive coverage from mainstream media that aligns with the movements' objectives. Protesters need to engage in "newsworthy" practices to garner enough attention for media coverage. However, this can be problematic as audiences are increasingly aware and skeptical of what is being portrayed in the media as authentic versus artificial actions. For some more critical readers, the media is said to act as a stage where these protesters are able to put on a "performance". These type of comments suggest that the actions of the protesters is a hoax, as some users claim that the protesters are only acting a certain way when the cameras are rolling. Comments suggested that the leaders of the movement, Joshua Wong of Scholarism and Benny Tai of OCLP, were only at protest sites to make media appearances. Other users commented on the students' technologically savvy abilities to "manipulate" the media for their own means, such as picking up garbage and overexaggerating violence with the police.

Due to the "biased" nature of SCMP's coverage, users took upon themselves to curate and reference other articles that demonstrate alternative perspectives of the protests. Other commenters suggested that SCMP's lack of reports on how the movement has impacted Hong Kong's economy continues to demonstrate SCMP's lack of 
impartiality in generating quality journalism. Portraying a lack of concern for the movement's economic impact on Hong Kong reinforced the Democracy as Remedy frame. This frame led some commenters to assume that SCMP's coverage was only supportive of the pan-democrat camp versus the dominant views of Hong Kong. Certain users expressed the demand for more "balanced coverage" to report on the views of the "silent majority" as well.

There were significantly fewer commenters that directly labeled WP's content as biased, as there was a great number of users expressing concern and agreeing with WP's Tiananmen 2.0 frame. Users debated more on the quality of democracy and international interventions made by the United States for democratic causes. What shifted the gears of WP's comment section was when Eric $\mathrm{Li}$, a venture capitalist and political scientist in Shanghai, wrote an editorial that deviated from the editorial staff at WP's position on the movement. For context, Li's article argued that the Umbrella Movement "is about inequality, not politics, so democracy can't fix the problem". Li contextualizes the movement in Hong Kong as part of a "global trend", where countries going through tough economic periods and are experiencing "social dislocation" tend to generate greater discontent to protest. For many commenters, the overall tone of Li's message was to discourage the movement and displace blame from mainland China. Many commenters began to counter the points Li presented in his article, such as mentioning how public polls in Hong Kong were "brutally hacked" by China to manipulate the results to show that the majority of people in Hong Kong do not support the movement. Overall, commenters in WP were less apt to define its content as "biased" and used the platform to fuel political discourse based on contemporary and historical issues. The most noticeable 
push back from audience comments in WP's articles was during Li's editorial, as it appeared to be out of place and provided a stark contrast of views against WP's prodemocracy discourses.

The same treatment of critique did not escape the comment section of GT. As mentioned previously in this chapter, audiences used gaps in GT's discourse to reinforce the movement's key purpose. The conspiracy theories put forth in the reports by GT were questioned as propagandistic and a form of "brainwashing", blaming the protests on the West. Some commenters were able to recognize areas of framing and bias in GT's reports. For example, GT news discourses affirmed that China has done far more in helping democratize Hong Kong than Britain has in the past. Some commenters were able to backtrack and provide evidence that it was China who threatened to attack in 1952 if Britain took action in democratizing Hong Kong. Some commenters were able to identify when GT reported quotes and information out of its original context. They were able to provide links and provide subjectively, better explanations.

The ability to comment on these news articles has allowed commenters to go out of their way to fact check and share additional missing information they perceived to be pertinent to the topic. Another way for commenters to compensate for what they perceived to be biased reporting was to share their own insights, opinions, theories, and personal stories. Users justified their positions in a variety of ways, such as links to other media sources, YouTube videos, social media pages, and most commonly, anecdotal evidence. While media frames tend to provide a fixed view on one side of the topic, the comment sections have provided a number of reasons why some Hongkongers choose to support or not to support the movement. Commenters that come from a different 
generation than the student protesters expressed general discontent with radical change. They argued that social and economic conditions in Hong Kong have improved for citizens after the Handover, and wish not to disturb the city radically. However, they are open to progressive changes, which they see as progress with NPCSC's decision. A large number of commenters have also expressed their support for the movement, but not the methods of occupying, as it is seen as a great disturbance to the city.

Individuals that support the movement aim to paint a larger picture that contextualizes the movement historically through Hong Kong's relationship with mainland China and Britain. They sense that China's influence over Hong Kong has increasingly been an attempt to dissolve its identity, through attempting to implement a national education system onto Hong Kong. Issues addressed in Chapter Three, such as the lack of upward social mobility, rising costs of living, and the general economic and political uncertainty of Hong Kong are expressed by commenters as reasons to support the movement. The majority of commenters who are against the movement express more short-term concerns, such as not being able to send their kids to school due to the protests, inconveniences to work, and effects on the economy. Overall, commenters who support the movement are able to contextualize its purpose to the greater good of Hong Kong, while non-supporters are more concerned with the short-term consequences.

\subsection{Discussion: The Paradox of News Framing}

While commenters engage in the consumption of news content, it appears that most commenters are also increasingly critical, skeptical, and aware of journalistic practices, such as framing. What can be described here is a paradox of news framing. 
While commenters have expressed that "quality" journalism must remain impartial and inform readers of all sides of a story, this very request goes against the concept of framing, as certain ideas and issues are made to be more salient than others. Oftentimes, this can be intentional, as journalists must uncover or defend one angle of an issue or event to construct the narrative of a story. But sometimes, this process can be unintentionally engrained within journalistic constraints. The pressure to report and produce a story as fast as possible may lead to shortcuts in fact checking and the research process. Also, some frames and the bias they possess are simply embedded into the enduring values of society, such as the unquestioning doubt that democratic pursuit is key in Western societies, as discussed in Chapter Four.

Although the paradox of news framing appears to be problematic, it can be advantageous in the online news environment. Due to the normative ideals of journalism to be impartial and report on "facts" of the world, there are more engaged audiences who wish to uphold this standard. By evaluating the accuracy of the news source, commenters are able to build upon news discourses. News frames are instrumental due to their ability to generate discussions. Audience awareness of news frames, bias, and inaccurate interpretations of events influence engaged news audiences to seek multiple news sources for coverage on one event or issue. Although not all audiences may do so, those who have are able to provide alternative accounts. Prior to open comment sections, audiences still had many ways to express their opinions online, such as forums and blogs. There were always, and will always be, multiple perspectives of a story to be shared. However, what comment sections accomplish are their ability to provide another platform of expression that condenses the words and opinions of a specific topic into one cohesive 
space. Commenters recognize the reach mainstream news articles have on audiences. They comment with the knowledge and hope that a broader audience will see their message. Although feedback is not a direct expectation from commenters, the commenting space affords the possibility for greater discussions. Since it is impossible for media to escape bias, comment sections provide the opportunity for audiences to deconstruct the bias and reveal more sides of the story. By doing so, commenters extend the discourse set by news media, as comments from news articles can be just as valuable as the information within the articles itself.

While it is beneficial for social movement organizations to have mainstream news discourses engage in frame alignment processes, the same may not apply for audience responses. Audience responses do not necessarily need to be aligned with a social movement organization's frames to be effective in strengthening, promoting, or supporting a movement's message. Negative responses that confront the narrative of the movement's preferred frame provide opportunities for discussion. This was supported by evidence of commenters actively engaging with messages that were considered conflicting or contradictory. As this movement affected the lives of many local and international Hongkongers, the reporting of the movement was important to those seeking more knowledge and understanding of the events, which also led to the contribution of audience insights. In this case, there were a significant number of commenters with critical opinions who were vocal in expressing their attitudes that went against certain media messages. While originally assumed that positive frame alignment from the comments would strengthen support for the protest movement, it was discovered that negative and unsupportive comments that did not align with the social movement 
organization's frame were also productive. Negative comments that did not align with the media or movement's frames provided opportunities for supporters of the movement to justify their position. In the case of coverage from SCMP, comments from non-supporters gave supporters the chance to defend the protesters and their cause. Comments from supporters were generally more positive and pointed to the movement as a cause that would give Hong Kong a brighter future. On the other hand, non-supporters tended to produce more negative and uncivil comments. Supporters have more opportunities to garner sympathy through their comments, justifying the movement as beneficial for Hong Kong long-term, despite temporary inconveniences.

Overall, the findings revealed a pattern of discussions initiated by critical commenters. Although some commenters did not always communicate in the most civil manner, the majority of critical comments were constructive and contained evidence to support their arguments. Users were more likely to comment when the news article did not align with their existing knowledge of an event or issue, or if the author's position did not support their own views. This occurred frequently in SCMP comments, as this movement heavily affected the city and Hongkongers worldwide. Commenters used SCMP's news articles to legitimate their own subjective social realities. Debating the nature of support over the movement in Hong Kong was a way that allowed commenters to objectify their reality by comparing it to what the majority of society consents to. Depictions of the majority's support for the movement in Hong Kong was not aligned with many commenters, who then wished to share their own account and insights. At the same time, the Tiananmen 2.0 frame generated less dissenting comments because commenters dominantly agreed that China could be a threat to the protesters in Hong 
Kong. Accordingly, commenters in GT also countered the dominant discourses that constructed the Protesters as Manipulation frame by advancing the real purpose of the movement's goals in the comments.

It is through especially these "inaccuracies" explained by the paradox of news framing that generate gaps of opportunities to be filled by audiences. These "weaknesses" produced from news articles - whether it is inherent "bias" or the mistreatment of "facts" - can lead to circumstances that produce the further generation of knowledge. It can be argued that discourses within the comments can be equally - if not more valuable - than professionally produced news discourses. However, these discourses would not be as valuable without existing mainstream news platforms. Commenters do not simply state their acceptance or rejection of a frame, or treatment of an article - they elaborate their position. They explain why they agree or disagree by providing an additional perspective, a link to a different source, or synthesize broad concepts for others to share more of their subjective reality to others. While media frames provide one perspective of a story, the interactive space within comment sections are able to provide a fuller story and add to the creation of a greater "objective" reality.

\subsection{Conclusion}

This chapter examines the relationship between mainstream news and the audiences that consume its content. The findings have revealed the types of discourses these news frames produce by demonstrating how more engaged audiences interact with these frames. Overall, there was a tone of skepticism throughout all comment sections from SCMP, WP, and GT. These critical audiences expressed their recognition of certain 
news articles containing biased information. At the same time, many audiences have shared their concern and desire for impartiality within the news they consume. This produces a paradox in news framing, as the act of framing involves a process of selection. These more engaged audiences are recognizing problems in the journalistic treatment of certain news articles, as they attempt to fill in the gaps of misrepresentation or misinformation through commenting. In turn, they contribute to the value of a news story by providing alternative perspectives on one event or issue, making these comment sections a productive, interactive, communicative space that is increasingly prevalent in journalism today. 


\section{Chapter: Conclusion}

This study provides a snapshot on how the Umbrella Movement was represented in mainstream news coverage by revealing the most prominent micro and macro-leveled frames. At the same time, this research also catalogues audience responses to each frame to closely observe the types of discourse produced. Due to the varying geographical location of news sources, South China Morning Post (SCMP), the Washington Post (WP), and Global Times (GT), their discourses also revealed insights on cross-national framing. These frames played a role in objectifying a particular representation of reality, both instrumentally towards the social movement and theoretically aligned with societal enduring values. Audience responses within corresponding comment sections did not always adhere to the suggested enduring values, nor accepted the frames that were presented in news discourses. Instead, the majority of commenters were critical towards news discourses, provoked discussions, and revealed supplemental and alternative perspectives on the movement. The comment spaces of online discourses act as interactive communicative spaces that provide opportunities for new perspectives to emerge.

The ways in which each news source framed the Umbrella Movement is a product of history. The strong and prevalent pro-democracy movement in Hong Kong has influenced the ways in which Hong Kong news outlets portray the movement. In light of Hongkongers' continuous struggle to achieve democracy, SCMP discourses must also be representative of public sentiments. Thus, the Democracy as Remedy frame aligns with the movement's goals and seeks to amplify the idea that Hong Kong can be fixed with 
democracy. With the United States' history in monitoring Hong Kong's relation with China and past engagements with building democracies, WP discourses are inclined to cover the movement positively towards the protesters. At the same time, WP discourses reference China's violent history with the 1989 Tiananmen student protests as a reflection to the more contemporary Umbrella Movement. The Tiananmen 2.0 frame extends the issues surrounding the protests to one about China's previous and possible future human rights violations. On the opposing end, discourses from GT attempt to erase China's history and any negative depictions of the state. Thus, all discourses attempt to stifle the movement and strengthen the positive image of the Central government. The Protester as Manipulation frame discounts the true purpose of the movement and generates a conspiracy theory that is based off of speculation rather than evidence.

More engaged audiences aim to fill the gaps left by news frames with their own interpretation and opinion of the movement and its events. The majority of pushback against SCMP's Democracy as Remedy frame stemmed from the notion that democracy itself would not make the situation better in Hong Kong. Using democracy to advance the movement's purpose was seen as a cover for other issues, such as separatism from the state, resentment against mainland, and the rising wealth gap in Hong Kong. Commenters were able to contextualize the movement to Hong Kong's historical and societal issues. Many of the themes explored in Chapter Three, such as the rejection of mainland identity and discontent towards the rising costs of living, were also apparent in the comments. 
After years of fighting for democracy in Hong Kong, there is an underlying sense of hopelessness among commenters who reject the Democracy as Remedy frame.

Findings revealed that a great number of commenters agreed with the Tiananmen 2.0 frame produced in WP. Commenters asserted that China's authoritarian regime must be held accountable for its actions with everybody's eyes on Hong Kong. This led to a greater discussion about the United States' role in democratizing nations and questioned why the American government was not helping Hong Kong. These discourses produced by WP reinforce the enduring values held by Western democratic societies. At the same time, these discourses were effective because audiences held the same enduring values that democracy is a virtuous reason to protest. However, the results from the United States' previous history with democratizing nations leaves commenters skeptical of the benefit of foreign intervention and the United States' true intentions.

GT discourses that form the Protesters as Manipulation frame generated comments that countered the negative portrayal of protesters. While GT discourses discounted the movement as simply an extremist group in Hong Kong generating chaos, commenters expressed the movement's intention as the journey to achieving universal suffrage by 2017. At the same time, there were also an equal amount of agreeable comments that supported the Umbrella Movement as a conspiracy theory motivated by the United States to weaken China's power. Others focused more on the soft power influence Western societies have over the younger generation in Hong Kong, as students were described to be the most vulnerable in society. Commenters that share positive messages that are aligned with the movement's intentions are important, as they provide 
an outlet for mainlanders to see alternative perspectives of the movement that would otherwise be censored.

This research has reinforced the idea that audiences do not simply reiterate news frames that are produced. They are often critical of the content they are consuming and have a repertoire of knowledge accumulated by personal experience as well as external references. While news articles are expected to produce quality journalism that remains impartial when covering events and issues, the practice of framing involves the process of selection when constructing news discourse. This paradox of news framing provides opportunities for communicative action. The Umbrella Movement was a story that required a constructed narrative that had clearly defined positions of support or rejection. Underneath the veil of support or rejection contains macro-frames that indicate the key problems and favourable treatments. Knowing which frames are accepted or rejected provides greater insight to the types of discussions held about particular issues and events within the Umbrella Movement. In doing so, commenters participate in the construction of their perceived objective social reality by adding in pieces of their subjective realities.

\subsection{Implications}

The ability for comments to represent all audience responses is impossible. However, there was still a significant amount of interactions within the comments, demonstrating the importance of these news stories and issues surrounding the Umbrella Movement. Out of the total 6,212 comments included in the corpus, averaging approximately 80 comments per news article studied, there were predominantly unique users and comments. All the comment sections studied were timely and disabled after 14 
days, capturing a snapshot of relevant discourse. Users who sign up to comment must also create accounts with verified email addresses. Sites also contain rules about multiple log-ins, which tend to discourage users from producing repetitive spam content. The ability for the community to self-monitor itself by flagging comments that violate the site's guidelines also act as a way to ensure discourses are appropriate within the comments. However, some implications remain when studying the relationship between news frames and user comments. While the online comment space affords the ability to examine audience discourses, it can be challenging to determine its representativeness over audiences at large. Generally, comments tended to represent more polarizing, dissenting, or counter viewpoints, which suggest that commenters may not be representative of the general audience. Average readers may not feel inclined to comment in comparison to readers with stronger beliefs, which generate a perceived polarization of an issue. However, the ability to comment online anonymously can also enable readers to communicate their true opinions, rather than self-censoring themselves in favour of responses that fit within societal norms.

The nature of the open platform can lead to constraints in determining the authenticity of discourses. It can be possible that pro-movement discourses may have been added predominantly by members of the movement or the pan-democratic camp in Hong Kong. It is also possible that anti-movement discourses may have been produced by "wumaos" who work to spread propagandistic messages by the Central government. Although the constraints of comment guidelines put forth by news sites tend to minimize spammers and moderate comments, it may still be possible that not all discourses are genuine and representative of average readers. While comment sections produce a 
platform for audiences to share their thoughts and opinions, they can also be a space for manipulators to infiltrate. This is a trade-off when examining comments online, as it is difficult to decipher the representative nature of comments due to the democratizing quality of the online space.

\subsection{Limitations}

As a Master's thesis, there were time constraints and limits in the scope of research and theories that could be explored. The findings selected the most dominant macro-frames. However, due to the interpretive nature of qualitative analysis, there is potential for more than one reading of the dominant frames selected from each news source. Using Van Gorp's (2010) method to build each frame allowed researcher subjectivity to be minimized in the findings. While all comments and quotes of my findings could not be included, all content that constructed the corpus are open to the public for others to study as well. It may also be possible that the relationship between news frames and corresponding comments in this case may not be representative of all audience interactions online, due to the unpredictable nature of comments and individual expression. While critical commenters sprung productive discourses in this study due to the critique or rejection of news frames, the same responses may not apply to another issue using similar methodology. Also, due to analyzing all comments by date and time, this study did not take into account of the algorithmic structure of the online comments. For example, top rated comments or top comments that include the most responses are often organized earlier in the comment section. These comments have a greater possibility of being read and thus, could potentially influence how and if the reader 
decides to participate as well. If the majority of comments are negative, then users may feel inclined to hold back on their opposing opinions, stifling their desire to comment.

\subsection{Recommendations for Future Work}

The frames revealed from the news discourses analyzed can only provide a representation for a limited period of time, from the NPCSC's decision to the week after the Key Event. While the timeline of articles spanned for almost two months, this research would benefit from the continuous cataloging of news frames produced by SCMP, WP, and GT regarding the Umbrella Movement. Although the protesters are no longer on the streets, the movement is still ongoing and alive. Seeing the evolution of these news frames can provide greater insight on the framing processes of social movements. At the same time, analyzing corresponding audience comments can reveal any changes in attitudes towards this movement and host discussions on new issues that have emerged. Lastly, research that takes into account of news framing from online articles should continue to study new areas of the comment space. While this research focused on all comments, future research should also study comments in the perspective of a real user's experience, adhering to the algorithmic structure of a website by reading "top comments" first. This structure may reveal insights on the most controversial topics that generate discussion, or most agreeable opinions. This research suggests that although online comments may not be representative of public opinion, they still contain valuable opinions from the public that are worthy of exploring when studying news frames. 


\section{References}

Benford, R.D., and Snow, D.A. (2000). Framing Processes and Social Movements: An Overview and Assessment. Annual Review of Sociology, 26, 611-639.

Berger, P.L. and Luckmann, T. (1966). The Social Construction of Reality. London: Penguin Books.

Bhatia, A. (2015). Construction of Discursive Illusions in the 'Umbrella Movement'. Discourse \& Society, 26(4), 407-427.

Boyle, M. P., McLeod, D.M., and Armstrong, C.L. (2012). Adherence to the Protest Paradigm: The Influence of Protest Goals and Tactics on News Coverage in U.S. and International Newspapers. International Journal of Press/Politics, 17(2), 127144.

Brown, K. (2012). The Communist Party of China and Ideology. China: An International Journal, 10(2), 52-68.

Chan, J.M. (2005). Hong Kong Styled 'People Power': Mobilization in the July 1 Demonstration and the Reconstruction of the Politics of Public Opinion. In C.H. 
Ng, T.L. Lui, and E. Ma (Eds.), Hong Kong Styled Cultural Studies (pp. 58-74). Hong Kong University Press.

Chan, J. M. (2014). Hong Kong's Umbrella Movement. The Round Table, 103(6), 571580 .

Chan, J.M., and Lee, F.L.F. (1984). The Journalistic Paradigm on Civil Protests: A Case Study of Hong Kong. In A. Arno and W. Dissanayake (Eds.), The News Media in National and International Conflict (pp. 183-202). Boulder, CO: Westview.

Chan, J. M., and Lee, F.L.F. (2007). Media and Large-Scale Demonstrations: The ProDemocracy Movement in Post-handover Hong Kong. Asian Journal of Communication, 17(2), 215-228.

Cheng, J.Y.S. (2014). New Trends of Political Participation in Hong Kong. In Cheng, J. Y.S. (Ed.), New trends of political participation in Hong Kong (pp. 3-34). Hong Kong: City University of Hong Kong Press.

Chow, P.A. (2015). Police-Related Statements During the Umbrella Movement in Hong Kong - "Laying Hands Down" or an Attempt at Discursive Formation. Inter-Asia Cultural Studies, 16(3), 470-487.

Chyi, H.I., and McCombs, M. (2004). Media Salience and the Process of Framing: Coverage of the Columbine School Shootings. Journalism and Mass Communication Quarterly, 81(1), 22-35.

Coe, K., Kenski, K., and Rains, S.A. (2014). Online and Uncivil? Patterns and Determinants of Incivility in Newspaper Website Comments. Journal of Communication, 64, 658-679.

Dahlberg, L. (2011). Re-constructing Digital Democracy: An Outline of Four "Positions". New Media \& Society, 13, 855-972.

D'Angelo, P., and Kuypers, J.A. (2010). Introduction: Doing News Framing Analysis. In D’Angelo, P. and Kuypers, J.A. (Eds.), Doing News Framing Analysis: Empirical and Theoretical Perspectives (pp. 1-13). Routledge.

Deng, Z. (2009). The Formation of a School Subject and the Nature of Curriculum Content: An Analysis of Liberal Studies in Hong Kong. Journal of Curriculum Studies, 41(5), 585-604. 
de Vreese, C.H., Peter, J., and Semetko, H.A. (2011). Framing Politics at the Launch if the Euro: A Cross-National Comparative Study of Frames in the News. Political Communication, 18(2), 107-122.

Di Cicco, D.T. (2010). The Public Nuisance Paradigm: Changes In Mass Media Coverage of Political Protest Since The 1960s. Journalism \& Mass Communication Quarterly, 87(1), 135-153.

Edelman, M. (1988). Constructing the Political Spectacle. Chicago: University of Chicago Press.

Entman, R. M. (1991). Framing US Coverage of International News: Contrasts in Narratives of the KAL and Iran Air Incidents. Journal of Communication, 41(4), 627.

Entman, R.M. (1993). Framing: Toward Clarification of a Fractured Paradigm. Journal of Communication, 43(4), 51-58.

Flanagan, P. (2014). Hong Kong: Cultural Transformation of the Public Sphere. In Curry, J. and Hanstedt, P. (Eds.), Reading Hong Kong, Reading Ourselves (pp. 66-89). City University of Hong Kong Press.

Gamson, W.A. (1988). Political Discourse and Collective Action. In Klandermans, B., Kriesi, H., and Tarrow, S. (Eds.), From Structure to Action: Comparing Social Movements Research Across Cultures (pp. 219-244). Greenwich, CNT: JAI Press.

Gamson, W.A. (1992). Talking Politics. New York, NY: Cambridge University Press.

Gamson, W.A., and Wolfsfeld, G. (1993). Movement and Media as Interacting Systems. Annals of the American Academy of Political and Social Sciences, 528, 114-125.

Gans, H.J. (1979). Deciding What's News: A Study of CBS Evening News, NBC Nightly News, Newsweek, and Time. New York: Pantheon Books.

Gargan, E.A. (1997). China Resumes Control of Hong Kong, Concluding 156 Years of British Rule. New York Times. Retrieved August 1, 2015 from http://www.nytimes.com/learning/general/onthisday/big/0630.html. 
Garrett, D. (2015). Counter-Hegemonic Resistance in China's Hong Kong: Visualizing Protest in the City. Springer.

Garrett, D., and Ho, W.C. (2014). Hong Kong at the Brink: Emerging Forms of Political Participation in the New Social Movement. In Cheng, J. Y.S. (Ed.), New Trends in Hong Kong's Participation. City University of Hong Kong Press.

Gitlin, T. (1980). The Whole World is Watching: Mass Media in the Making \& Unmaking of the New Left. Berkeley: University of California Press.

Goffman, E. 1974. Frame Analysis: An Essay on the Organization of Experience. New York, NY: Harper \& Row.

Gottlieb, J. (2015). Protest News Framing Cycle: How The New York Times Covered Occupy Wall Street. International Journal of Communication, 9, 231-253.

Guilford, G. (2014). The Secret History of Hong Kong's Stillborn Democracy. Retrieved August 1, 2015, from http://qz.com/279013/the-secret-history-of-hong-kongsstillborn-democracy/.

Habermas, J. (1962/1989). The Structural Transformation of the Public Sphere. Cambridge, MA: MIT Press.

Hall, S. (1973). Encoding and Decoding in the Television Discourse. Birmingham: Centre for Contemporary Cultural Studies.

Hall, S. (1999). Representation and the Media. Northampton, Media Education Foundation.

Hall, S. (1982). The Rediscovery of "Ideology": Return of the Repressed in Media Studies. In M. Gurevitch, T. Bennett, J. Curran, and J. Woollacott (Eds.), Culture, Society, and the Media. London: Methuen.

Hall, S. (1980). Encoding/Decoding. In S. Hall, D. Hobson, A. Lowe \& P. Willis (Eds.), Culture, Media, Language: Working Papers in Cultural Studies, 1972-1979 (pp. 128-138). London: Hutchinson.

Hertog, J.K., and McLeod, D.M. (2001). A Multiperspectival Approach to Framing Analysis: A Field Guide. In S.D. Reese, O.H. Gandy, \& A.E. Grant (Eds.), 
Framing Public Life: Perspectives on Media and our Understanding of the Social World (pp. 139-161). Mahwah, NJ: Erlbaum.

Holton, A., Lee, N., and Coleman, R. (2014). Commenting on Health: A Framing Analysis of User Comments in Response to Health Articles Online.

Iyengar, S. (1991). Is Anyone Responsible?: How Television Frames Political Issues. Chicago, IL: University of Chicago Press.

Kant, I. (1970). The Active Mind: The Judgements of Experience. In E. Kuykendall (Ed.) Philosophy in the Age of Crisis (pp. 346-355). New York: Harper \& Row.

Kwon, K.H., and Moon, S. (2009). The Bad Guy is One of Us: Framing Comparison Between the US And Korean Newspapers and Blogs about the Virginia Tech Shooting. Asian Journal of Communication, 19(3), 270-288.

Lam, J. T.M. (2014). The Occupy Central Movement and Political Reform in Hong Kong In Cheng, J. Y.S. (Ed.), New Trends of Political Participation in Hong Kong (pp. 447-480). City University of Hong Kong Press.

Larson, C. (2011). China's Fox News. Foreign Policy. Retrieved from http://foreignpolicy.com/2011/10/31/chinas-fox-news/.

Lee, A.Y.L., and Ting, K.W. (2015). Media and Information Praxis of Young Activists in the Umbrella Movement. Chinese Journal of Communication, 8(4), 376-392.

Lee, E-J. (2012). That's not the way it is: How User-Generated Comments on the News affect perceived Media Bias. Journal of Computer-Mediated Communication, 18, $32-45$.

Lee, E-J., and Jang, Y.J. (2010). What do Others' Reactions to News on Internet Portal Sites tell us? Effects of Presentation Format and Readers' need for Cognition on Reality Perception. Communication Research, 37. 825-846.

Lee, F.L.F., and Chan, J.M. (2015). Digital Media Activities and Mode of Participation in a Protest Campaign: A Study of the Umbrella Movement. Information, Communication \& Society, 19(1), 4-22.

Lee, F.L.F., and Chan, J.M. (2011). Media, Social Mobilization, and Mass Protests in Post-Colonial Hong Kong: The Power of a Critical Event. Routledge. 
Lee, P.S.N., So, C.Y.K., and Leung, L. (2015). Social Media and Umbrella Movement: Insurgent Public Sphere in Formation. Chinese Journal of Communication, 4(8), 356-375.

Lim, T.W. (2015). The Aesthetics of Hong Kong's "Umbrella Revolution" in the First Ten Days: A Historical Anatomy of the First Phase (27 Sep 2014 to 6 Oct 2014) of Hong Kong's Umbrella Revolution. East Asia, 32, 83-98.

Liu, Y. (2015). Yellow or Blue Ribbons: Analysing Discourses in Conflict in the Televized Government-Student Meeting During the Occupy Movement in Hong Kong. Chinese Journal of Communication, 8(4), 456-567.

Luk, B.H.K. (1991). Chinese Culture in the Hong Kong Curriculum, Heritage and Colonialism. Comparative Education Review, 24(4), 650-658.

Manosevitch, E., and Walker, D. (2009). Reader Comments to Online Opinion Journalism: A Space of Public Deliberation. $10^{\text {th }}$ International Symposium on Online Journalism. Austin, TX.

McAdam, D., McCarthy, J.D., and Zald, M.N. (1996). Comparative Perspectives on Social Movements: Political Opportunities, Mobilizing Structures, and Cultural Framings. New York, NY: Cambridge University Press.

McQuail, D. 1994. Mass Communication Theory: An Introduction. London: Sage.

Morley, D. 1980. The Nationwide Audience: Structure and Decoding. British Film Institute.

Mushkat, R. (1992). Peaceful Assembly. In Raymond Wacks (Ed.), Human Rights in Hong Kong. New York: Oxford University Press.

Newman, N., Levy, D.A.L., and Nielsen, R.K. (2015). Reuters Institute Digital News Report 2015: Tracking the Future of News. Retrieved August 31, 2015, from $\mathrm{http}: / / \mathrm{www}$.digitalnewsreport.org/.

Nossek, H. (2004). Our News and Their News: The Role of National Identity in the Coverage of Foreign News. Journalism, 5(3), 343-368. 
Occupy Central with Love and Peace. (n.d.). Retrieved June 1, 2015, from https://oclphkenglish.wordpress.com/about-2/manifesto/.

Ortmann, S. (2015). The Umbrella and Hong Kong's Protracted Democratization Process. Asian Affairs, 46(1), 32-50.

Pan, Z. and Kosicki, G.M. (1993). Framing Analysis: An Approach to News Discourse. Political Communication, 10, 55-75.

Petersen, C.J. (2005). Introduction. In Fu, H.L., Petersen, C.J., and Young, S.N.M. (Eds.), National Security and Fundamental Freedoms: Hong Kong's Article 23 Under Scrutiny (pp. 1-11). Hong Kong: Hong Kong University Press.

Price, V. (1988). Public Aspects of Opinion: Linking Levels of Analysis in Public Opinion Research. Communication Research, 15(4), 659-679.

Reese, S.D. (2010). Finding Frames in a Web of Culture: The Case of the War on Terror. In D’Angelo, P. and Kuypers, J.A. (Eds.), Doing News Framing Analysis: Empirical and Theoretical Perspectives (pp. 17-42). Routledge.

Rodriguez, C., Ferron, B., and Shamas, K. (2014). Four Challenges in the Field ff Alternative, Radical and Citizens' Media Research. Media, Culture \& Society, $36(2), 150-166$.

Rowe, I. (2015). Deliberation 2.0: Comparing the Deliberative Quality of Online News User Comments Across Platforms. Journal of Broadcast \& Electronic Media, 59(4), 539-555.

Ruiz, C., Domingo, D., Mico, J.L., Diaz-Noci, J. Meso, K., and Masip, P. (2011). Public Sphere 2.0? The Democratic Qualities of Citizen Debates in Online Newspapers. The International Journal of Press/Politics, 16, 463-487.

Sagan, A. (2014). Joshua Wong: Meet the Teen Mastermind of Hong Kong's 'Umbrella Revolution'. Retrieved June 12, 2015, from http://www.cbc.ca/news/world/joshuawong-meet-the-teen-mastermind-of-hong-kong-s-umbrella-revolution-1.2784105.

Scholarism. (n.d.). About Us. Retrieved June 1, 2015 from http://scholarism.com/?page_id=281. 
Snow, D.A., and Benford, R.D. (1988). Ideology, Frame Resonance, and Participant Mobilization. In Klandermans, B., Kriesi, H., and Tarrow, S. (Eds.), From Structure to Action: Social Movements Participation Across Cultures (pp. 197217). Greenwich, CT: JAI Press.

Snow, D.A., Rochford, E.B., Worden, S.K., and Benford, R.D. (1986). Frame Alignment Processes, Micromobilization, and Movement Participation. American Sociological Review, 51(4), 464-481.

Tang, G. (2015). Mobilization by Images: TV Screen and Mediated Instant Grievances in the Umbrella Movement. Chinese Journal of Communication, 8(4), 338-355.

The Basic Law of the HKSAR. (2012). Retrieved September 12, 2015, from http://www.basiclaw.gov.hk/en/basiclawtext/chapter_4.html.

Toepfl, F., and Piwoni, E. (2015). Public Spheres in Interaction: Comment Sections of News Websites as Counterpublic Spaces. Journal of Communication, 65, 465-488.

Valinsky, J. (2015). Washington Post Tops New York Times Online for First Time Ever. Digiday. Retrieved October 12, 2015, from http://digiday.com/publishers/comscore-washington-post-tops-new-york-timesonline-first-time-ever/.

Van den Bulck, J. (1999). Mediation: Toward a Media Theory of the Social Construction of Reality. Communicatio, 25(1\&2), 3-11.

Van Gorp, B. (2010). Strategies to Take Subjectivity Out of Framing Analysis. In D’Angelo, P. and Kuypers, J.A. (Eds.), Doing News Framing Analysis: Empirical and Theoretical Perspectives (pp. 84-109). Routledge.

Wallack, L., Dorfman, L., Jernigan, D., and Themba-Nixon, M. (1993). Media Advocacy and Public Health. Newbury Park, CA: Sage.

Washington Post Media. (2013). MarketBook 2013. Retrieved September 15, 2015, from https://www.washingtonpostads.com/sites/default/files/MarketBook2013.pdf.

Western iMedia. (2015). South China Morning Post Focuses on Growing International Audience. Retrieved September 15, 2015, from http://www.inma.org/blogs/world- 
congress/post.cfm/south-china-morning-post-focuses-on-growing-internationalaudience.

West, G., and Blumberg, R. (1991). Reconstructing Social Protests from a Feminist Perspective. In West, G., and Blumberg, R.L. (Eds), Women and Social Protest (pp. 3-36). Oxford University Press.

Zald, M., and McCarthy, D. (Eds.). (1987). Social Movements in an Organizational Society. New Brunswick, NJ: Transaction. 


\section{Appendix:}

\begin{tabular}{|c|c|c|c|}
\hline Date & Organization & Type & Article Name \\
\hline 29/08/2014 & GT & News Report & Extremists cannot Prevail in Hong Kong \\
\hline $31 / 08 / 2014$ & SCMP & News Report & $\begin{array}{l}\text { Occupy Central's Benny Tai Declares } \\
\text { 'Era of Civil Disobedience for Hong } \\
\text { Kong' }\end{array}$ \\
\hline $01 / 09 / 2014$ & GT & News Report & $\begin{array}{l}\text { NPC Decision Vital for Development of } \\
\text { Hong Kong's Political System }\end{array}$ \\
\hline 01/09/2014 & GT & News Report & $\begin{array}{l}\text { Hong Kong Radical Camp is a Paper } \\
\text { Tiger }\end{array}$ \\
\hline 02/09/2014 & GT & News Report & $\begin{array}{l}\text { China Reaffirms Opposition to Foreign } \\
\text { Interference in Hong Kong Affairs: FM } \\
\text { Spokesman }\end{array}$ \\
\hline 03/09/2014 & GT & News Report & $\begin{array}{l}\text { Hong Kong Election Principles Cater to } \\
\text { Genuine Universal Suffrage }\end{array}$ \\
\hline 03/09/2014 & GT & News Report & $\begin{array}{l}\text { Extremists Risk Dragging Hong Kong } \\
\text { into Chaos }\end{array}$ \\
\hline 05/09/2014 & GT & News Report & $\begin{array}{l}\text { Overseas Chinese, Experts Laud } \\
\text { Development of Hong Kong's Political } \\
\text { System }\end{array}$ \\
\hline 06/09/2014 & GT & News Report & $\begin{array}{l}\text { Experts, Overseas Chinese Support } \\
\text { Beijing's Decision on Hong Kong's } \\
\text { Electoral Reform }\end{array}$ \\
\hline $06 / 09 / 2014$ & GT & News Report & $\begin{array}{l}\text { China urges UK to Stop Interference in } \\
\text { Hong Kong's Affairs }\end{array}$ \\
\hline $11 / 09 / 2014$ & GT & News Report & $\begin{array}{l}\text { Hong Kong Student Strike Doesn't } \\
\text { Signal Social Sentiment }\end{array}$ \\
\hline 28/09/2014 & SCMP & News Report & $\begin{array}{l}\text { Police Fire Tear Gas as Occupy Central } \\
\text { Spreads and Ranks of Protests Swell }\end{array}$ \\
\hline 28/09/2014 & GT & News Report & $\begin{array}{l}\text { Chinese VP Urges Studies on Hong } \\
\text { Kong, Macao Issues }\end{array}$ \\
\hline
\end{tabular}




\begin{tabular}{|c|c|c|c|}
\hline $29 / 09 / 2014$ & GT & News Report & $\begin{array}{l}\text { Street Movement Ruins Hong Kong } \\
\text { Image }\end{array}$ \\
\hline $29 / 09 / 2014$ & SCMP & News Report & $\begin{array}{l}\text { Classical Music Gives Way to brollies } \\
\text { and Barricades }\end{array}$ \\
\hline $29 / 09 / 2014$ & SCMP & News Report & $\begin{array}{l}\text { Occupy Central - Day Two: Full Report } \\
\text { of Day's Events }\end{array}$ \\
\hline $29 / 09 / 2014$ & SCMP & Op Ed & $\begin{array}{l}\text { Authorities had Ample Time to Avoid } \\
\text { Occupy Collision }\end{array}$ \\
\hline $29 / 09 / 2014$ & SCMP & News Report & $\begin{array}{l}\text { Solidarity with Hong Kong Rallies } \\
\text { Planned Worldwide as Facebook Turns } \\
\text { Yellow in Support of Protesters }\end{array}$ \\
\hline $29 / 09 / 2014$ & SCMP & News Report & $\begin{array}{l}\text { Occupy Central - Night Two: Full Report } \\
\text { of Night's Events }\end{array}$ \\
\hline $30 / 09 / 2014$ & WP & News Report & $\begin{array}{l}\text { Holiday Turnout for Hong Kong Protests } \\
\text { Could Sway Future of Democracy } \\
\text { Protests }\end{array}$ \\
\hline $30 / 09 / 2014$ & WP & News Report & $\begin{array}{l}\text { For Hong Kong Students, Getting } \\
\text { Arrested Could Mean a Complicated Visa } \\
\text { Process }\end{array}$ \\
\hline $30 / 09 / 2014$ & WP & $\begin{array}{l}\text { Editorial } \\
\text { Board }\end{array}$ & $\begin{array}{l}\text { US Should Send Signal to China in } \\
\text { Support of Hong Kong Democracy } \\
\text { Movement }\end{array}$ \\
\hline $30 / 09 / 2014$ & GT & Op Ed & Protests Choke Hong Kong \\
\hline $30 / 09 / 2014$ & SCMP & News Report & $\begin{array}{l}\text { Riot Police pull out but OC Protesters In } \\
\text { HK are Unmoved }\end{array}$ \\
\hline $30 / 09 / 2014$ & SCMP & News Report & Police come to the aid of the Protesters \\
\hline $30 / 09 / 2014$ & SCMP & News Report & $\begin{array}{l}\text { CY Leung digs in as he admits OC } \\
\text { Protests Could Last "A Long Time" }\end{array}$ \\
\hline $30 / 09 / 2014$ & SCMP & News Report & $\begin{array}{l}\text { Occupy Central - Day Three: Full Report } \\
\text { on the Day's Events }\end{array}$ \\
\hline $30 / 09 / 2014$ & SCMP & News Report & Top 10 Highlights of OC so far \\
\hline $30 / 09 / 2014$ & SCMP & News Report & $\begin{array}{l}\text { OC Goes Global: Solidarity Protests } \\
\text { Planned for Dozens of Cities Worldwide }\end{array}$ \\
\hline
\end{tabular}




\begin{tabular}{|l|l|l|l|}
\hline $30 / 09 / 2014$ & SCMP & Op Ed & “Against my fear, I see that you hope” \\
\hline $30 / 09 / 2014$ & SCMP & NewsReport & $\begin{array}{l}\text { OC Night Three: Full Coverage of the } \\
\text { Night's Events }\end{array}$ \\
\hline $01 / 10 / 2014$ & WP & News Report & $\begin{array}{l}\text { Russian View: West Stirs up Hong Kong } \\
\text { as a way to Punish - Russia }\end{array}$ \\
\hline $01 / 10 / 2014$ & SCMP & News Report & $\begin{array}{l}\text { 'Umbrella Revolution” Weathers Storm, } \\
\text { and CY Leung Admits Protests set to last }\end{array}$ \\
\hline $01 / 10 / 2014$ & SCMP & News Report & $\begin{array}{l}\text { Impromptu Leaders Turn Occupy's } \\
\text { 'Guerrilla' action into a Highly Focused } \\
\text { Operation }\end{array}$ \\
\hline $01 / 10 / 2014$ & SCMP & News Report & $\begin{array}{l}\text { Occupy Central - Day Four: Full } \\
\text { Coverage of the Day's Events }\end{array}$ \\
\hline $01 / 10 / 2014$ & SCMP & Op Ed & $\begin{array}{l}\text { Q\&A: Chinese Activist Scholar Teng } \\
\text { Biao on how Occupy Central Affects } \\
\text { Mainland Activism }\end{array}$ \\
\hline $01 / 10 / 2014$ & SCMP & Op Ed & $\begin{array}{l}\text { We are only asking for Beijing to keep its } \\
\text { Promise on Democracy }\end{array}$ \\
\hline $01 / 10 / 2014$ & SCMP & News Report & $\begin{array}{l}\text { Beijing's top man in Hong Kong } \\
\text { Dismissive of Democracy Protests }\end{array}$ \\
\hline $01 / 10 / 2014$ & SCMP & News Report & $\begin{array}{l}\text { Demonstrators set CY Thursday Deadline } \\
\text { to Resign with Threat to step up Protests }\end{array}$ \\
\hline $01 / 10 / 2014$ & SCMP & News Report & $\begin{array}{l}\text { Occupy Central - Night Four: Full } \\
\text { coverage of all the Night's Events }\end{array}$ \\
\hline $02 / 10 / 2014$ & WP & News Report & $\begin{array}{l}\text { How Hong Kong's Protesters won the } \\
\text { Hearts of the City's Business People }\end{array}$ \\
\hline $02 / 10 / 2014$ & WP & News Report & $\begin{array}{l}\text { Hong Kong's Crossed Arms and Other } \\
\text { Protest Gestures around the World }\end{array}$ \\
Hit Hong Kong
\end{tabular}




\begin{tabular}{|l|l|l|l|}
\hline 02/10/2014 & SCMP & News Report & $\begin{array}{l}\text { Occupy Central - Day Five: Full } \\
\text { Coverage of the Day's Events }\end{array}$ \\
\hline $02 / 10 / 2014$ & SCMP & News Report & $\begin{array}{l}\text { We belong to Hong Kong: Thousands } \\
\text { Gather at Solidarity Events in 64 Cities } \\
\text { Worldwide }\end{array}$ \\
\hline $02 / 10 / 2014$ & SCMP & News Report & $\begin{array}{l}\text { Occupy Central Night Five: Full } \\
\text { Coverage of the Night's Events }\end{array}$ \\
\hline $03 / 10 / 2014$ & WP & Op Ed & What China promised Hong Kong \\
\hline $03 / 10 / 2014$ & SCMP & News Report & $\begin{array}{l}\text { Occupy Central - Day Six: Full Coverage } \\
\text { of the Day's Events }\end{array}$ \\
\hline $03 / 10 / 2014$ & SCMP & News Report & $\begin{array}{l}\text { Mainland Chinese Youths Launch } \\
\text { Facebook Campaign to Support Hong } \\
\text { Kong Protesters }\end{array}$ \\
\hline $03 / 10 / 2014$ & SCMP & News Report & $\begin{array}{l}\text { Anonymous' Hacker Group Brings Down } \\
\text { DAB, Occupy Central Websites }\end{array}$ \\
\hline $03 / 10 / 2014$ & SCMP & News Report & $\begin{array}{l}\text { Occupy Central Night Six: Full Coverage } \\
\text { of the Night's Events }\end{array}$ \\
\hline $04 / 10 / 2014$ & WP & News Report & $\begin{array}{l}\text { Hong Kong's Students want you to Stop } \\
\text { Calling their Protest a 'Revolution' }\end{array}$ \\
\hline $04 / 10 / 2014$ & WP & News Report & $\begin{array}{l}\text { For Hong Kong's Pro-Democracy } \\
\text { Activists, Exhaustion Overtakes } \\
\text { Enthusiasm and Hope }\end{array}$ \\
\hline $04 / 10 / 2014$ & SCMP & News Report & $\begin{array}{l}\text { Occupy Central - Day Seven: Full } \\
\text { Coverage of the Day's Events } \\
\text { Hong Kong ASAP }\end{array}$ \\
\hline $05 / 10 / 2014$ & GT & News Report & $\begin{array}{l}\text { Filipinos in Hong Kong Warned Against } \\
\text { Joining Protests }\end{array}$ \\
\hline Coverage of the Night's Events
\end{tabular}




\begin{tabular}{|l|l|l|l|}
\hline 05/10/2014 & GT & News Report & $\begin{array}{l}\text { Singapore FM sees Anti-China Bias in } \\
\text { Western Media Reports on Movement in } \\
\text { Hong Kong }\end{array}$ \\
\hline 05/10/2014 & SCMP & Op Ed & The Dark Before Dawn \\
\hline $05 / 10 / 2014$ & SCMP & News Report & $\begin{array}{l}\text { Occupy Central - Night Eight: Full } \\
\text { Coverage of the Night's Events }\end{array}$ \\
\hline $06 / 10 / 2014$ & WP & Op Ed & $\begin{array}{l}\text { The Umbrella Revolution won't Give } \\
\text { Hong Kong Democracy. Protesters } \\
\text { should Stop Calling for it. }\end{array}$ \\
\hline $06 / 10 / 2014$ & GT & News Report & $\begin{array}{l}\text { Some Protesters in Hong Kong Decide to } \\
\text { Withdraw, Classes to Resume }\end{array}$ \\
\hline $06 / 10 / 2014$ & WP & News Report & $\begin{array}{l}\text { Protesters try to memorialize Hong } \\
\text { Kong's 'Umbrella Revolution' before it } \\
\text { Disappears }\end{array}$ \\
\hline $06 / 10 / 2014$ & WP & News Report & $\begin{array}{l}\text { In Beijing, Support for Dialogue in Hong } \\
\text { Kong but not Democracy }\end{array}$ \\
\hline $06 / 10 / 2014$ & SCMP & Op Ed & $\begin{array}{l}\text { Hongkongers Abroad Play a Key Role in } \\
\text { Occupy Movement }\end{array}$ \\
\hline $06 / 10 / 2014$ & SCMP & Op Ed & $\begin{array}{l}\text { Beijing's Hard Line the Real Case of the } \\
\text { Protests }\end{array}$ \\
\hline $06 / 10 / 2014$ & SCMP & News Report & $\begin{array}{l}\text { Beijing's Rallying Cry to Hong Kong } \ldots \\
\text { and 1.3 Billion Mainlanders }\end{array}$ \\
\hline $06 / 10 / 2014$ & SCMP & News Report & $\begin{array}{l}\text { Occupy Central - Day Nine: Full } \\
\text { Coverage of the Day's Events }\end{array}$ \\
\hline $07 / 10 / 2014$ & WP & News Report & $\begin{array}{l}\text { The Colorful World of Hong Kong's } \\
\text { Protest Art }\end{array}$ \\
\hline News Report & $\begin{array}{l}\text { Hong Kong Student Leaders agree to } \\
\text { Talks but say Government 'Insincere' }\end{array}$ \\
\hline News Report & $\begin{array}{l}\text { Occupy Central - Day Ten: Full } \\
\text { Coverage of the Day's Events }\end{array}$ \\
\hline Coverage of the Night's Events
\end{tabular}




\begin{tabular}{|c|c|c|c|}
\hline 08/10/2014 & SCMP & Op Ed & $\begin{array}{l}\text { No Revolution, but let's hope Youth } \\
\text { Protests are a Catalyst for Change }\end{array}$ \\
\hline 08/10/2014 & GT & News Report & $\begin{array}{l}\text { China Again Voices Opposition to } \\
\text { Foreign Interferences in Hong Kong }\end{array}$ \\
\hline 08/10/2014 & SCMP & News Report & $\begin{array}{l}\text { Occupy Central Day Eleven: Full } \\
\text { Coverage of the Day's Events }\end{array}$ \\
\hline 08/10/2014 & SCMP & Op Ed & $\begin{array}{l}\text { Poetry Reading for Hong Kong Protesters } \\
\text { Prompts Detentions in Beijing }\end{array}$ \\
\hline 09/10/2014 & WP & News Report & $\begin{array}{l}\text { Hong Kong Government Backs out of } \\
\text { Talks; Students Vow Renewed Protests }\end{array}$ \\
\hline 09/10/2014 & GT & News Report & $\begin{array}{l}\text { Hong Kong Must Treasure Economic } \\
\text { Vitality }\end{array}$ \\
\hline 09/10/2014 & GT & News Report & $\begin{array}{l}\text { Overseas Chinese call for Peaceful, } \\
\text { Rational Resolution to Hong Kong } \\
\text { Protests }\end{array}$ \\
\hline 09/10/2014 & SCMP & Op Ed & $\begin{array}{l}\text { Jimmy Lai Chee-ying says he 'hasn't } \\
\text { given one cent' to Occupy Central } \\
\text { Organizers }\end{array}$ \\
\hline 09/10/2014 & SCMP & News Report & $\begin{array}{l}\text { Supporters urge Occupy protesters to } \\
\text { Unite Amid Mixed Messages Over Talks }\end{array}$ \\
\hline 09/10/2014 & SCMP & News Report & $\begin{array}{l}\text { Occupy Central - Day 12: Full Coverage } \\
\text { of the Day's Events }\end{array}$ \\
\hline 10/10/2014 & SCMP & News Report & $\begin{array}{l}\text { Umbrella Movement allows Tycoons to } \\
\text { Occupy Central }\end{array}$ \\
\hline $10 / 10 / 2014$ & SCMP & News Report & $\begin{array}{l}\text { Occupy Central - Day 13: Full Coverage } \\
\text { of the Day's Events }\end{array}$ \\
\hline $10 / 10 / 2014$ & SCMP & News Report & $\begin{array}{l}\text { Jackie Chan Criticizes Economic Cost of } \\
\text { Occupy Central, calls on Hongkongers to } \\
\text { "love the country" }\end{array}$ \\
\hline
\end{tabular}

